\title{
Squamous Cell Carcinoma of the Upper Aerodigestive Tract: Precursors and Problematic Variants
}

Bruce M. Wenig, M.D.

Department of Pathology, Beth Israel Medical Center, New York, New York

KEY WORDS: Genetics, Pathogenesis, Premalignant lesions, Squamous cell carcinoma, Upper aerodigestive tract.

Mod Pathol 2002;15(3):229-254

In the head and neck region, the most common lesion encountered by the otolaryngologist and the pathologist relates to alterations of the surface squamous epithelium. This review will focus on the squamous epithelial alterations of the upper aerodigestive tract (UADT), including premalignant lesions and squamous cell carcinoma (SCC).

Premalignant squamous epithelial lesions of the UADT present diagnostic challenges in that the majority of dysplastic epithelial changes are of the keratinizing type, to which the continuum of mild to moderate to severe dysplasia to invasive carcinoma that characterizes the nonkeratinizing dysplasias does not consistently apply. This results in problems in the histologic grading of these changes and raises questions about what constitutes a diagnosis of severe dysplasia. In this context, the justification for using the designation carcinoma in situ relative to keratinizing dysplasia becomes questionable. I will attempt to address these issues focusing on the spectrum of squamous dysplasias (nonkeratinizing and keratinizing), as well as on the justification of using the term carcinoma in situ for the keratinizing dysplasias of the UADT.

The section on head and neck SCC (HNSCC) will include the diagnostic criteria for recognizing early or microinvasive SCC, pitfalls in differentiating benign lesions that histologically simulate invasive SCC, and the prognostic factors related to HNSCC. There are numerous variants of HNSCC (Table 1). Some of these variants include papillary SCC, verrucous carcinoma (VC), spindle cell squamous car-

Copyright $(2) 2002$ by The United States and Canadian Academy of Pathology, Inc.

VOL. 15, NO. 3, P. 229, 2002 Printed in the U.S.A.

Date of acceptance: September 27, 2001.

Address reprint requests to: Bruce M. Wenig, M.D., Department of Pathology, Beth Israel Medical Center, First Avenue at $16^{\text {th }}$ Street, New York, NY 10003. cinoma, basaloid SCC, nasopharyngeal carcinoma, and adenoid SCC. The diagnostic criteria and diagnostic problems associated with these specific subtypes of HNSCC will be discussed.

The last section of this manuscript includes a brief discussion on genetic aspects of HNSCC, specifically directed at the concept of field cancerization and clonality of multifocal SCC, as well as etiologic agents associated with HNSCC. Finally, emerging diagnostic and prognostic modalities that are currently being used for HNSCC are presented.

\section{TERMINOLOGY}

The alterations of the surface epithelium include the following clinical and pathologic terms:

Leukoplakia is a clinical term that describes any white lesion on a mucous membrane. A leukoplakic lesion is usually associated with a mucosal thickening and is not indicative of underlying dysplastic/ malignant lesion.

Erythroplakia is a clinical term that describes any red lesion on a mucous membrane. An erythroplakic lesion is often indicative of an underlying dysplastic/malignant lesion.

Hyperplasia is a thickening of an epithelial surface as a result of an absolute increase in the number of cells.

Pseudoepitheliomatous hyperplasia (PEH) is an exuberant reactive or reparative overgrowth of squamous epithelium displaying no cytologic evidence of malignancy; it may be mistaken for an invasive squamous carcinoma.

Keratosis is an increase in the amount of surface keratin (hyperkeratosis), often with prominent granular cell layer and overlying orthokeratin (anuclear keratotic cells), often admixed with parakeratin (flattened keratotic cells with pyknotic nuclei)

Dyskeratosis is an abnormal keratinization of epithelial cells.

Dysplasia and intraepithelial neoplasia represent a spectrum of abnormal epithelial maturation (dysplasia) and cellular aberrations (atypia) that may or 
TABLE 1. Head and Neck Squamous Cell Carcinoma (SCC) and Variants

Conventional SCC

Papillary SCC

Adenoid SCC

Verrucous carcinoma

Spindle cell squamous carcinoma

Basaloid SCC

Nasopharyngeal carcinoma

Adenosquamous carcinoma

may not precede an invasive carcinoma. Dysplasia is also referred to as atypia.

Carcinoma in situ (CIS) as classically defined represents full-thickness mucosal epithelial dysplastic change without violation of the basement membrane. For all intents and purposes, severe dysplasia is synonymous with CIS.

Early, superficially, or microscopic invasive SCC is defined as squamous carcinoma in which there is penetration of the basement membrane with invasion of the carcinoma into the underlying submucosal compartment.

\section{Clinical Alterations of the Surface Epithelium}

The clinical appearance of premalignant or "incipient" lesions of the mucosal surfaces of the upper aerodigestive tract include leukoplakic, erythroplakic, or speckled leukoplakia reflecting the presence of a white, red, or mixed white/red lesion, respectively. Among these clinical changes, erythroplakic lesions are commonly associated with ominous histopathologic alterations, including severe dysplasia, CIS, or invasive carcinoma. In contrast, leukoplakic lesions are not necessarily a premalignant lesion and may demonstrate a spectrum of histopathologic changes ranging from an increase surface keratinization without dysplasia to invasive keratinizing squamous carcinoma. Leukoplakic lesions, in contrast to erythroplakic lesions, tend to be well defined with demarcated margins. Although the risk of developing a malignancy in a leukoplakic lesion is low, there is still a risk (approximately $10-12 \%)$ of malignant transformation $(1,2)$ The clinical appearance of a mixed white and red lesion, called speckled leukoplakia, carries an intermediate risk between "pure" leukoplakic and "pure" erythroplakic lesions for the development of a malignancy (3), but speckled leukoplakia should be viewed as a variant of erythroplakia $(1,3,4)$. In a study of 236 patients with asymptomatic intraoral carcinoma, Mashberg and Feldman (4) reported that $64 \%$ of the lesions were red or predominantly red (erythroplakic), 23\% were equally red and white (speckled leukoplakia), and $12 \%$ were white or predominantly white (leukoplakic).
Histopathology of Squamous

Epithelial Neoplasia

Leukoplakia, erythroplakia, and speckled leukoplakia are not histopathologic terms. The qualitative intraepithelial alteration in a malignant direction is referred to as dysplasia. Dysplasia is for all intents and purposes synonymous with atypia, although dysplasia has been used in relation to architectural abnormalities, whereas atypia has been used for cytomorphologic changes.

Histologic criteria for the diagnosis of intraepithelial neoplasia of the UADT include both cytomorphologic and maturation abnormalities. These alterations include the proliferation of immature or "uncommitted" cells characterized by a loss of cellular organization or polarity, nuclear pleomorphism (variations in the size and shape of the nuclei), increase in nuclear size relative to the cytoplasm, increase in the nuclear chromatin (hyperchromasia) with irregularity of distribution, and increased mitoses, including atypical forms in all epithelial layers. The dysplastic changes may or may not be associated with keratosis and/or dyskeratosis. The locations of the architectural and cytomorphologic changes within the epithelium represent key diagnostic parameters in the assessment of UADT epithelial dysplasia.

The paradigm for grading epithelial dysplasia is the one used for the uterine cervix. In the uterine cervix, the "classic" or nonkeratinizing form of dysplasia commonly occurs. The increasing gradations of cervical dysplasia include mild (CIN I), moderate (CIN II), and severe (CIN III), with the latter representing full-thickness replacement of the squamous epithelium by atypical, small, immature basaloid cells and referred to as carcinoma in situ (Fig. 1). This grading scheme is reproducible and is clinically useful. However, the "classic" or nonkeratinizing dysplasia of the uterine cervix is uncommon in the UADT, especially in the laryngeal glottis (5). In contrast, most of the intraepithelial neoplasias of the UADT are keratinizing dysplasias. Using the definition of CIS of the uterine cervix that requires loss of maturation of squamous epithelium, a keratotic lesion cannot be CIS because keratosis requires maturation of the squamous epithelium. Therefore, the use of the specific term CIS in keratinizing dysplasias has been questioned (6) and is likely inappropriate in this setting. A more appropriate designation is of severe keratinizing intraepithelial dysplasia.

The criteria for evaluating keratinizing dysplasias are less defined, and the diagnosis of severe keratinizing intraepithelial dysplasia remains controversial. The definition of severe dysplasia in the UADT, especially in the laryngeal glottis, is broader than the highly reproducible pattern seen in the 

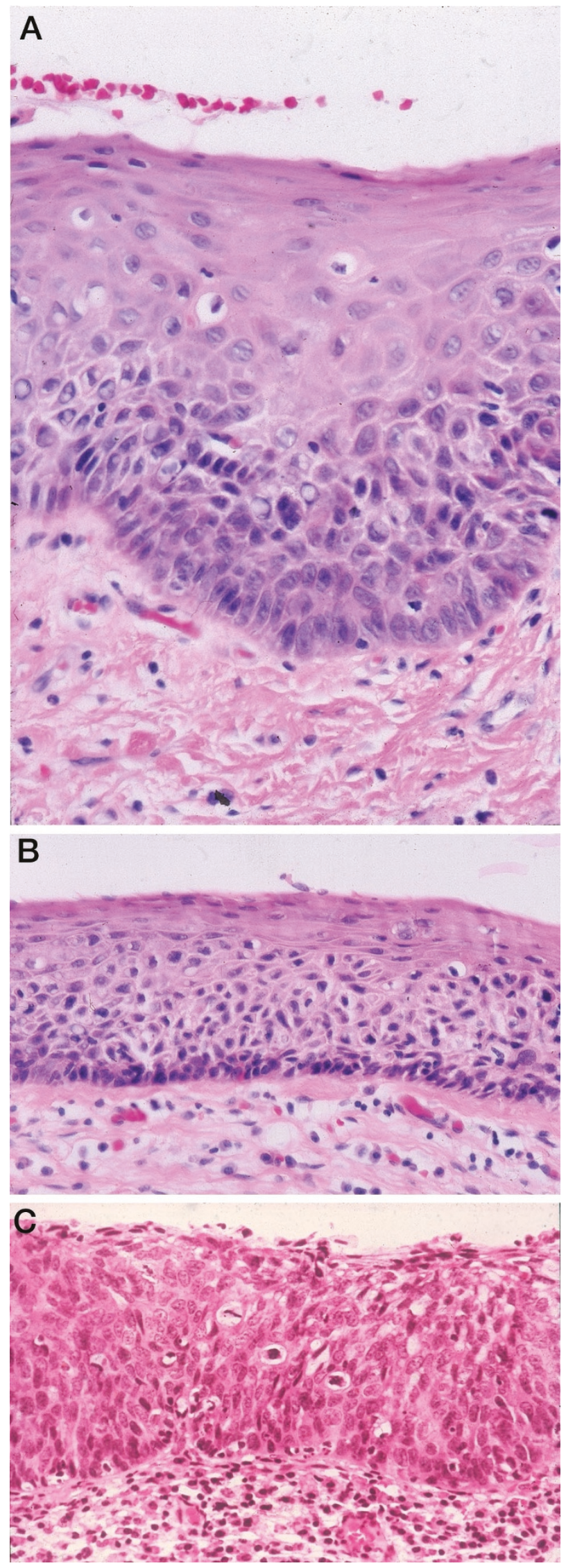

FIGURE 1. "Classic" or non-keratinizing dysplasia of the larynx. A, Mild dysplasia. B, Moderate dysplasia. C, severe dysplasia with fullthickness replacement of the squamous epithelium by atypical, small, immature basaloid cells also referred to as carcinoma in situ. uterine cervix and includes a microscopically heterogenous group of lesions (6). In the setting of keratinizing dysplasia, where surface maturation is retained with only partial replacement of the epithelium by atypical cells, severe dysplasia includes those lesions in which the epithelial alterations are so severe that there would be a high probability for progression to an invasive carcinoma if left untreated (Fig. 2). Severe dysplasia shows the presence of aberrant cell maturation with dyskeratotic cells and mitotic figures with or without atypical forms above the basal zone (7). These alterations often occur in the presence of surface keratinization. In the evaluation of UADT dysplasia, the presence of surface keratinization is not significant (8); however, finding dyskeratotic cells represents an important clue to the presence of significant dysplasia (9).

\section{Grading Epithelial Dysplasia of the UADT}

The histopathologic interpretation and grading of epithelial dysplastic changes in the upper aerodigestive tract is imprecise and subjective. Given the complexities in the issues relative to UADT intraepithelial lesions, confusion and misunderstandings may occur between the clinician and the pathologist that may result in inappropriate management of the patient. Uniformity in terminology is desirable so that there is a correlation between the pathologic diagnosis and the clinical import of that diagnosis. In an attempt to standardize the terminology of upper aerodigestive tract intraepithelial lesions using a grading system akin to that of the cervical mucosa, Crissman and Zarbo (10) used the terminology of squamous intraepithelial neoplasia (SIN), with SIN I equivalent to mild dysplasia, SIN II to moderate dysplasia, and SIN III to severe dysplasia. Similar gradations, but using the terminology of laryngeal intraepithelial neoplasia (LIN) have been proposed (11). More recently, the Ljubljana classification of laryngeal precancerous lesions was proposed (12). In this system, the terms used include simple hyperplasia (i.e., keratosis without atypia), abnormal hyperplasia (i.e., keratosis with atypia), atypical hyperplasia (i.e., severe dysplasia), and carcinoma in situ. These systems have conceptual validity but may not be entirely applicable from a practical standpoint in the UADT. At present, the preferred grading for dysplastic epithelial alterations of the UADT includes mild, moderate, and severe dysplasia, depending on the degree and extent of cellular and maturation alterations that are present.

Regardless of the terminology employed, close interaction between the pathologist and the clinician is required so that each individual understands 

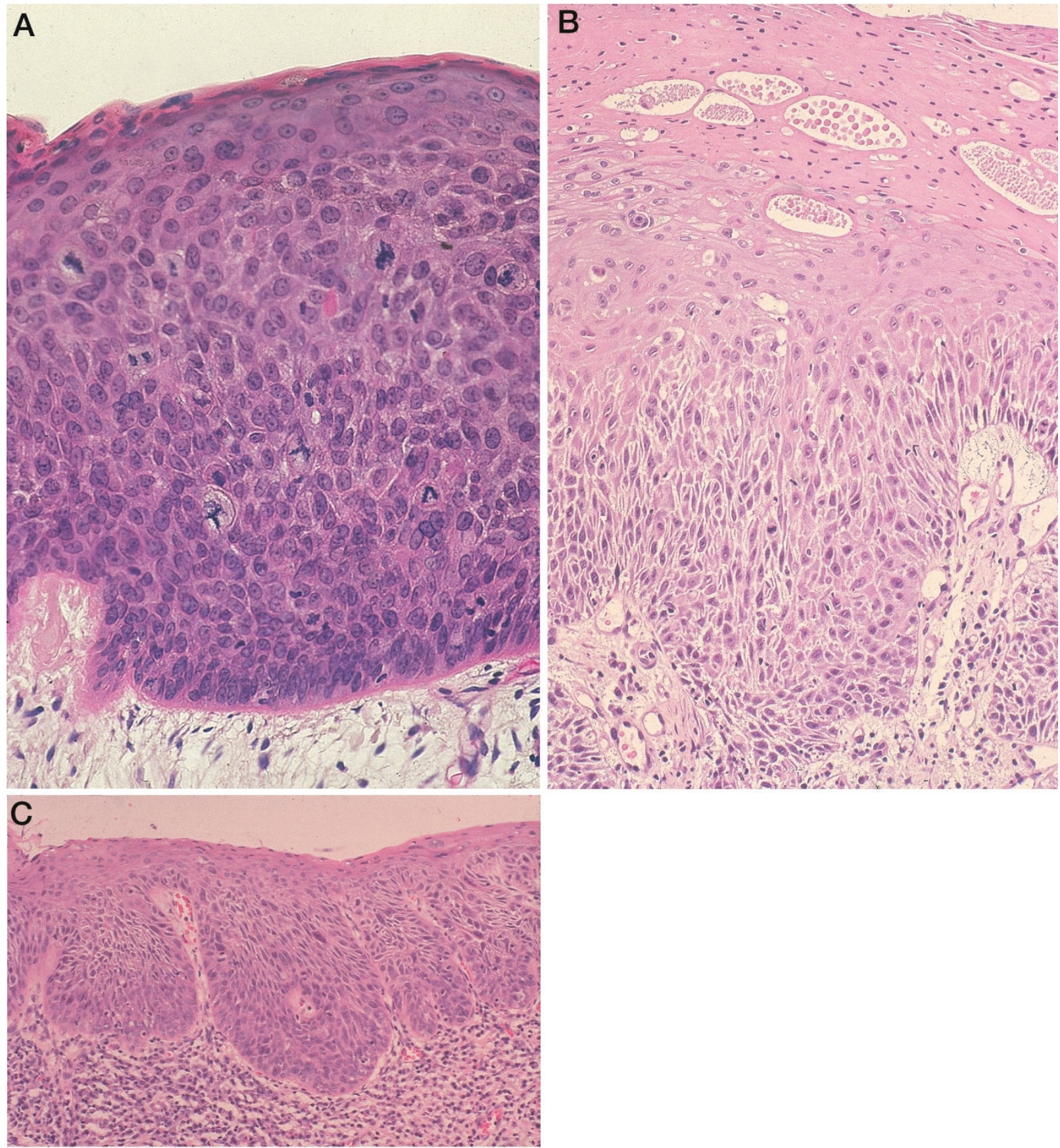

FIGURE 2. Keratinizing dysplasia of the larynx. A-C, examples of severe dysplasia where surface maturation is retained but the extent of the epithelial alterations are so severe that there is a high probability for the progression to invasive carcinoma if left untreated.

the impact of his or her respective findings and the import to the patient in therapy and prognosis.

\section{Risk of Progression}

The end point for the grading of dysplasia is to convey to the clinician what is the potential biologic behavior of a given epithelial lesion. Keratotic epithelium without dysplasia carries a very low risk of developing subsequent carcinoma, with reported incidences of 1 to $5 \%(10,12-18)$. In contrast, ker- atotic epithelium with dysplasia is associated with an increased risk for the subsequent progression or development of premalignant or overtly carcinomatous changes, varying from 11 to $18 \%(10,12-18)$ of cases. This risk of malignant transformation represents an increase of three to five times as compared with carcinoma arising in keratotic lesions without atypia. Bouquot and Gnepp (19) found greater variability relative to risk progression of keratosis with and without atypia in their review of the literature. Nevertheless, the potential value in grad- 
ing keratotic dysplasias is apparent from Barnes's review of the literature (18), in which the risk for developing invasive carcinoma in mild, moderate, and severe dysplasia was $5.7,22.5$, and $28.4 \%$, respectively. Other studies have shown that severe dysplasia is associated with increased incidences of persistent disease or progression to invasive carcinoma (20-23). Bauer and McGavran (24) indicated that if enough sections are taken, microinvasive carcinoma will be found in laryngeal lesions that have keratosis with cytologically atypical cells.

Another important point to recognize is the clinical concern attached to a diagnosis of severe keratinizing intraepithelial neoplasia. This clinical concern is due to the fact that severe dysplasia is often multifocal and frequently occurs adjacent to or near synchronous foci of invasive carcinoma. Further, this form of dysplasia has a rate of progression to invasive carcinoma that is greater than that of "classic" CIS $(20,23,25)$. A diagnosis of severe dysplasia requires therapeutic intervention, as well as clinical evaluation of the entire UADT to exclude the possible presence of additional foci of dysplasia or carcinoma.

In general, mild and moderate dysplasias are felt to be reversible alterations. Circumstantial evidence supports the idea that preinvasive dysplasias are potentially reversible after cessation or removal of an instigating factor such as tobacco use (26). The problem of predicting the malignant potential of a dysplastic lesion is greatest in cases of moderate dysplasia. It is virtually impossible to differentiate the moderately dysplastic lesions that are reversible from those that represent the earliest forms of neoplastic transformation (21). Therefore, a diagnosis of moderate dysplasia should engender enough concern to the clinician to warrant close patient follow-up. Recurrence or persistence of this dysplasia may be indicative of malignant transformation. The determination of whether a mild to moderate dysplasia is reactive or neoplastic, although a desirable goal, is not always achievable. The clinically abnormal lesions that show limited cytologic and maturation abnormalities falling under the designation of reactive atypias or hyperplastic lesions represent reversible changes that rarely, if ever, progress to carcinoma. These lesions are responsive to conservative management. Epithelial hyperplasia (acanthosis) is a common finding and can be seen without atypia or in association with atypia. In hyperplasia, there usually is an irregular contour to the basal zone, and there may be protrusion of the epithelium below adjacent epithelium, possibly suggesting a microinvasive carcinoma. A diagnosis of microinvasive carcinoma should be reserved for those examples in which there is definitive evidence of dissociated squamous cells at the epithelial-to-stromal interface.
Epithelial hyperplasias may be caused by an infectious agent (e.g., fungi), and fungal stains may be useful for identifying the causative microorganism.

Immunohistochemical evaluation for Type IV collagen and laminin has been used in the evaluation of intraepithelial lesions. Sakr et al. (27) found that basal lamina was prominent and continuous in normal and reactive hyperplasias, was usually prominent and continuous in mild to moderate dysplasia, and was thinned and occasionally discontinuous in severe dysplasia or carcinoma in situ.

\section{Microinvasive, Superficial, or "Early" Invasive SCC}

Microinvasive SCC is a cancer that infiltrates the superficial compartment of the lamina propria. As simple as this may appear, the diagnosis of superficially invasive SCC can be subjective, with no unanimous definition among pathologists. For laryngeal lesions, some authors consider microinvasive cancer to include the presence of scattered malignant cells within the submucosa just below the basement membrane (28) or within 1-2 mm of the basement membrane $(10,29,30)$, whereas other authors feel that microinvasive carcinoma is present when tongues or discrete foci of malignant epithelium invade through the basement membrane (31). Barnes (18) defines microinvasive carcinoma as invasive SCC that extends into the stroma by $\leq 0.5$ $\mathrm{mm}$, as measured from the adjacent (nonneoplastic) epithelial basement membrane. Irrespective of its specific definition, a diagnosis of microinvasive carcinoma excludes those lesions that are restricted to the surface epithelium or carcinoma in situ (Tis) and those carcinomas that are deeply invasive into muscle and cartilage and into extralaryngeal structures (T2 or greater tumors). Also, the presence of lymph-vascular space invasion would exclude a diagnosis of microinvasive carcinoma. Of note, extension of the dysplastic

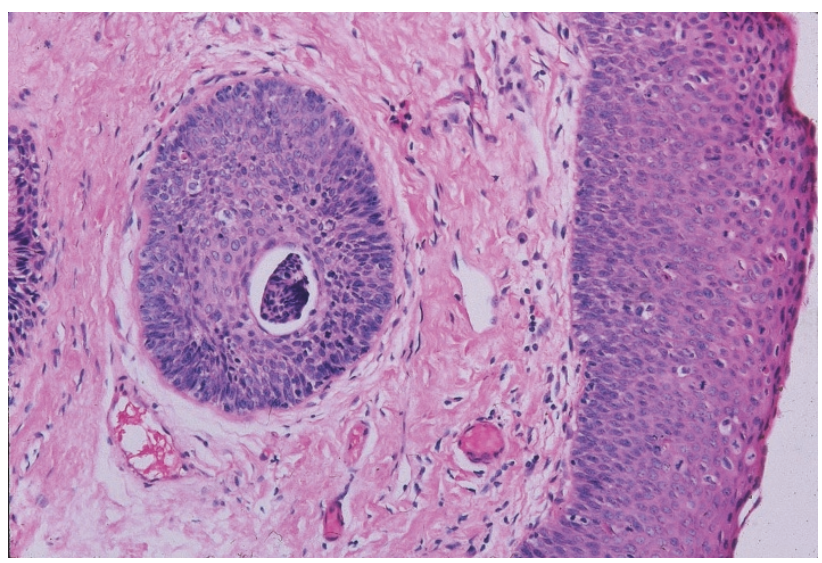

FIGURE 3. Extension of the dysplastic alterations to include seromucous glands is still considered as within the spectrum of carcinoma in situ. 
process to involve the seromucinous glands is still considered CIS and not invasive carcinoma (Fig. 3). The clinical manifestations and appearance of microinvasive SCC are similar to those of CIS. In the larynx, full cord mobility is present. Any dysfunction in vocal cord mobility (fixation) by definition means muscle invasion, which excludes a diagnosis of microinvasive cancer.

Histologically, microinvasive carcinoma can occur in two unrelated phases. The first is the devel- opment from and as a continuum of CIS (Fig. 4). The second is invasion from an epithelium demonstrating no evidence of CIS. In the upper aerodigestive tract, particularly in the larynx, severe dysplasia (i.e., CIS) is not a prerequisite for the development of an invasive SCC. Such invasive carcinomas "drop off" or "drop down" from the basal cell layer, with the overlying mucosa showing no evidence of dysplasia (Fig. 4). In all examples of invasive carcinoma, the invasive nests
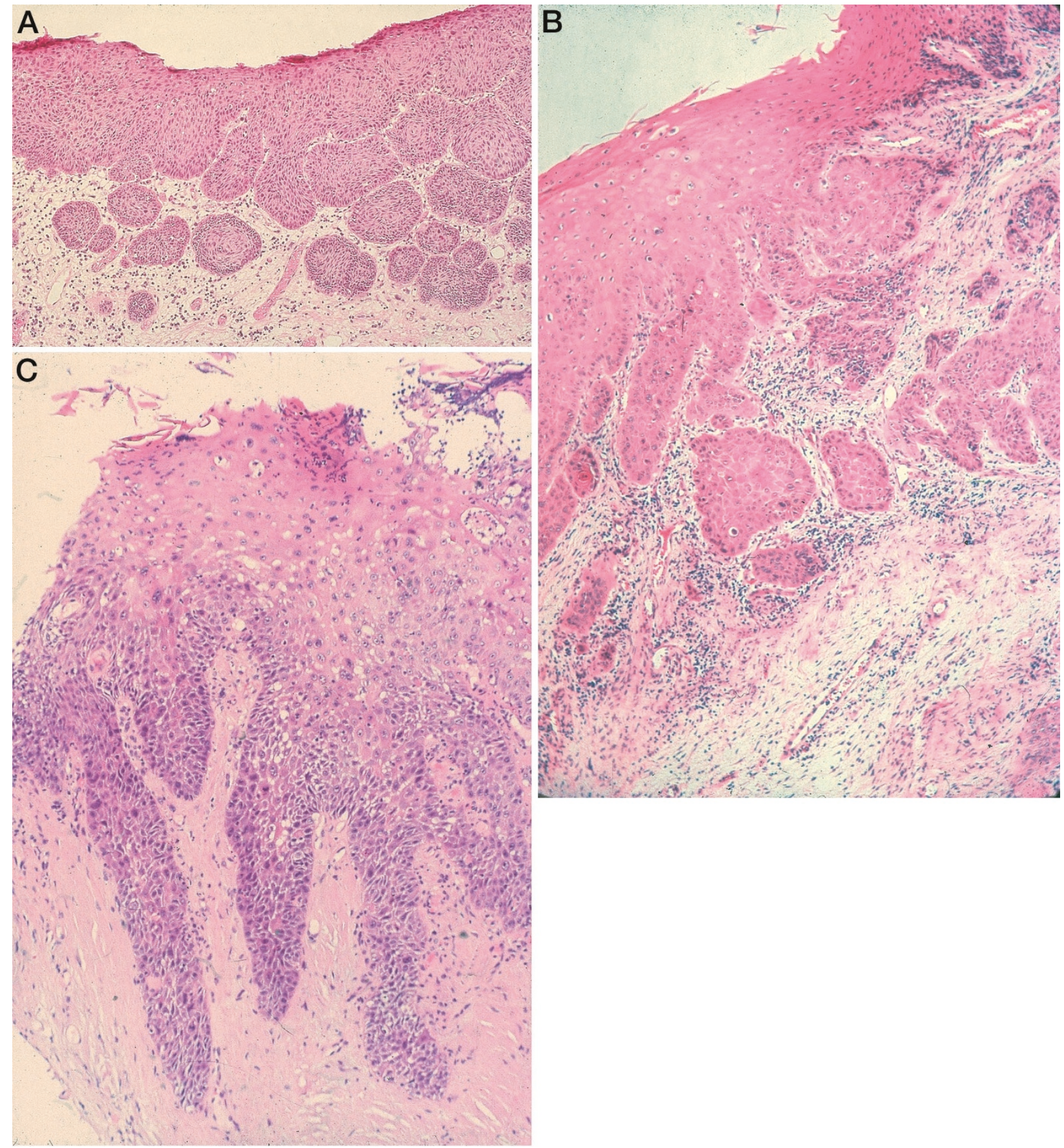

FIGURE 4. Microinvasive carcinoma of the larynx. A, the invasive carcinoma is arising as a continuum from carcinoma in situ (classic type). B, microinvasive ("drop-off") carcinoma arising from the basal area of an essentially non-dysplastic surface epithelium. C, in this illustration there appears to be no violation of the basement membrane, but the extent of downward growth and angulation of the rete are sufficient for a diagnosis of microinvasive carcinoma. 

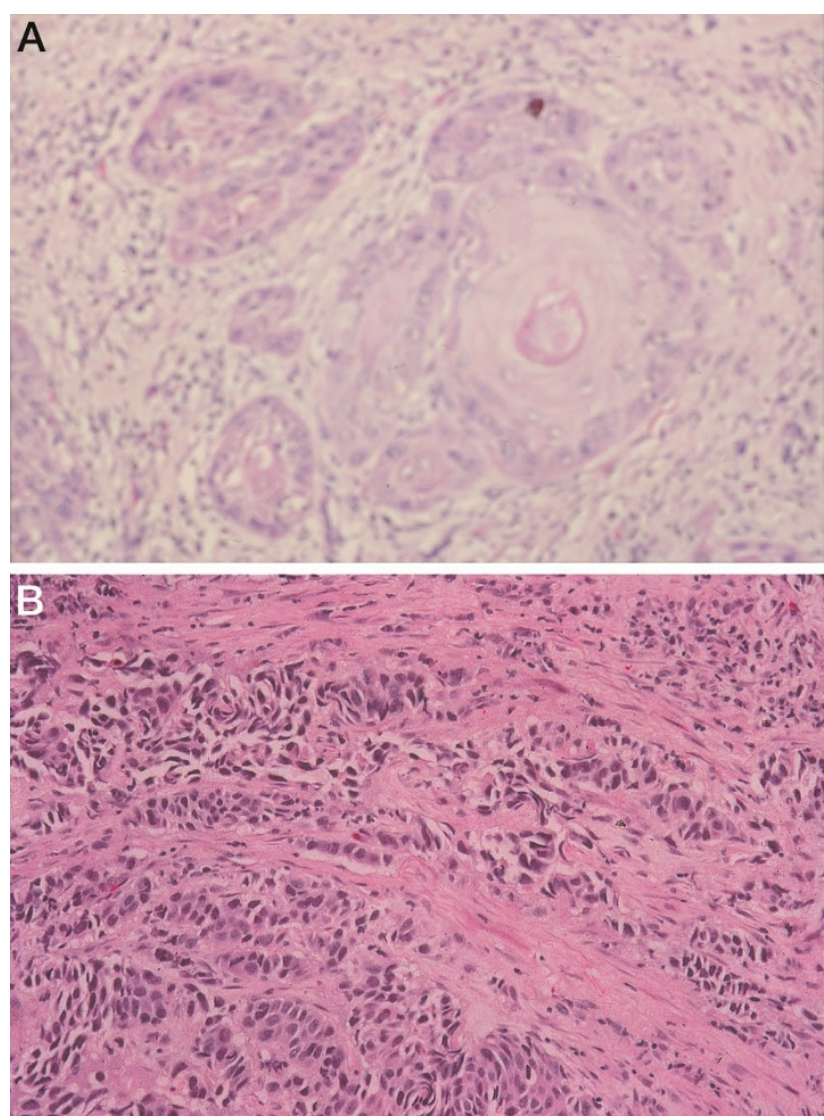

FIGURE 5. Invasive squamous cell carcinoma. A, cohesive or nested growth pattern. B, dyscohesive growth pattern. In both illustrations, there is desmoplastic stromal response to the presence of invasive carcinoma.

must be cytologically malignant with dysplastic changes, dyskeratosis, and mitotic figures, including atypical forms. The tumor nests have an irregular outline with infiltrative borders. The presence of invasive cancer generally results in stromal induction or a desmoplastic host response that includes edematous change immediately around the tumor nests with granulation tissue and fibrosis.

Microinvasive cancer is a biologically malignant lesion potentially capable of gaining access to lymphatic or vascular channels in the lamina propria that may result in metastatic disease. For microinvasive carcinoma of the laryngeal glottis, several studies have shown that the clinical significance is similar to CIS/severe dysplasia: with appropriate therapy (excision and/or radiotherapy), progression of disease from a microinvasive to a more invasive carcinoma does not occur $(22,23,28,29)$. This may be because of the earlier clinical manifestations produced by glottic cancers leading to an earlier diagnosis of cancer before it has invaded into deeper aspects of the larynx. Glottic microinvasive cancers are generally not associated with metastatic disease because the glottic portion of the larynx has quantitatively less lymph-vascular spaces as compared with the supra- and subglottis. In contrast to the laryngeal glottis, supraglottic microinvasive carcinomas are associated with metastatic disease in approximately $20 \%$ of patients (32)

The concept of so-called superficially extending carcinoma of the larynx and hypopharynx was introduced as the morphologic equivalent to early carcinoma of the upper gastrointestinal tract (18, $33,34)$. As it is defined, superficially extending carcinoma includes those SCC that invade beyond what is considered as microinvasion or superficial invasion (i.e., not beyond the lamina propria) without invasion into adjacent muscle or cartilage.

\section{Invasive SCC}

The clinical (gross) appearance of invasive SCC is quite variable and includes ulcerated, flat, exophytic, verrucoid, or papillary growths. The histologic appearance of invasive SCC may be as variable as the gross appearance without specific correlation between the gross appearance and the histopathologic findings. Invasive SCC of the UADT includes keratinizing and nonkeratinizing carcinomas varying from well to poorly differentiated. Severe dysplasia/CIS of the surface epithelium may be a com-
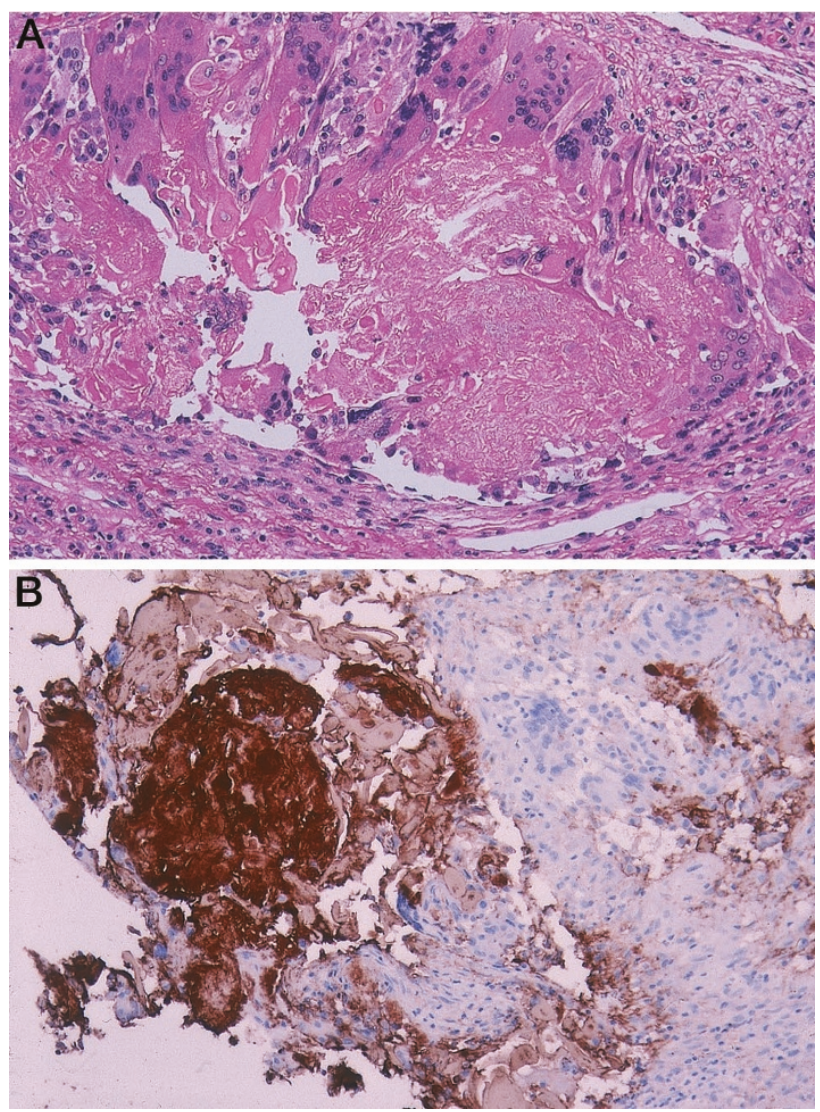

FIGURE 6. A, B, foreign body giant cell reaction in which the amorphous eosinophilic material proved to be cytokeratin positive. This was an example of laryngeal carcinoma in situ, and the presence of the keratin granuloma was indicative of invasive carcinoma. 
mon component found in association with invasive SCC; this component need not be present. For all types of SCC, the presence of invasion is diagnostic of a malignancy. Invasion can be as large cords or cohesive aggregates or can appear as single (dyscohesive) cells or small irregular aggregates (Fig. 5). A desmoplastic stromal response is a hallmark feature of invasive cancer. In addition, a foreign body reaction to keratin in the stroma (Fig. 6) may also assist in identifying the presence of invasion. Invasive cancer will efface the normal architecture and may be associated with lymph-vascular space invasion, neurotropism, and invasion into muscle, bone, and cartilage. Once the cancer invades beyond a few millimeters or extends into muscle, cartilage, or other soft tissue components outside the anatomic structure from which it originates, then the tumor is a higher clinical stage neoplasm with the potential for more aggressive behavior. Immunohistochemical studies have shown that that the presence or absence of basement membrane components around invasive cancer correlated with the pattern of tumor invasion (27). The pattern of tumor invasion (single cell versus large cords) represents an inherent biologic parameter of tumor aggressiveness $(10,27)$.

\section{Pitfalls in the Diagnosis of Invasive SCC}

Sampling is a major issue in the evaluation of SCC of the UADT. In the absence of adequate representative tissue including epithelial-to-stroma interface, one should be circumspect relative to a diagnosis of SCC. Diagnostic pitfalls in the diagnosis of SCC include pseudoepitheliomatous hyperplasia (35), necrotizing sialometaplasia (36), juxtaoral organ of Chievitz (36), and radiation atypia.

$\mathrm{PEH}$ is an exuberant reactive epithelial response to a variety of stimuli, including chronic inflammatory conditions, infections, trauma, and neoplasms. $\mathrm{PEH}$ is classically associated with granular cell tumor (GCT), which is a benign neoplasm of probable peripheral nerve sheath origin, which often occurs in the oral cavity (tongue, lips) and larynx. In the setting of GCT, the epithelial response may be so extensive as to be indistinguishable from SCC (Fig. 7). Close attention to the presence of the GCT intimately associated with the PEH will assist identifying this epithelial proliferation as reactive rather than neoplastic. To this end, S100 protein may be of assistance in identifying the presence of the GCT. Further, a helpful diagnostic clue in not diagnosing the PEH associated with GCT as malignant is the fact that the epithelial proliferation does not extend below the depth of the GCT. Infections such as fungi and mycobacteria may induce $\mathrm{PEH}$, simulating SCC. Fungi within the depth of the surface epithelium or even within the submucosa may re- sult in PEH of the surface epithelium (Fig. 8); special stains may be of assistance in the identification of fungal forms.

Necrotizing sialometaplasia (NS) represents a benign, self-healing (reactive) inflammatory process of salivary gland tissue that clinically and histologically may be mistaken for a malignant neoplasm. NS most commonly involves the intraoral minor salivary glands, in particular the palate, but major salivary glands as well as the minor salivary glands of virtually every site in the UADT can be affected. The most common presenting problem is that of a painless ulcerated lesion or a nodular swelling. The lesions are usually asymptomatic but may be associated with pain, numbness or a burning sensation, and dysphagia. The pathogenesis for NS is felt to be secondary to an ischemic event, with compromise of the vascular supply to salivary glands leading to ischemic necrosis. The ischemia may be iatrogenically induced after an operative procedure, trauma (after intubation), or radiotherapy. NS may occur de novo unassociated with a traumatic event or it may occur in association with other nonneoplastic lesions or in association with a neoplasm (benign or malignant).

NS typically appears as a deep, craterlike ulcerative lesion measuring from $1-3 \mathrm{~cm}$. However, the lesion may appear as a submucosal nodular swelling that may slough, leaving a craterlike ulcer.

The histologic appearance is that of lobular necrosis of the salivary glands, with preservation of the lobular architecture of the minor salivary glands. The histologic hallmark is squamous metaplasia of residual acinar and ductal elements. The necrotic lobules consist of acinus-sized pools of mucin, which may extend into adjacent tissue, eliciting a granulation tissue reaction with associated acute and chronic inflammation. The lobular architecture is maintained, and the metaplastic lobules vary slightly to moderately in size and shape and have smooth edges surrounded by granulation tissue and an intense mixed acute and chronic inflammatory reaction (Fig. 9). The squamous cells are bland in appearance, with uniform nuclei and abundant eosinophilic cytoplasm, with occasional preservation of ductal lumina or scattered mucocytes. Mucicarminophilic material is seen within lumina and within the cytoplasm of residual mucocytes. With regeneration, mitoses, individual cell necrosis, enlarged nuclei, and prominent nucleoli can be seen. Associated findings include ulcerated mucosa and PEH. PEH results when the metaplastic lobules present in excretory ducts and merge with surface epithelium. This reaction may be striking, making differentiation from an infiltrating SCC very difficult.

The juxtaoral organ of Chievitz (JOC) is a normal microscopic structure of unknown function located 

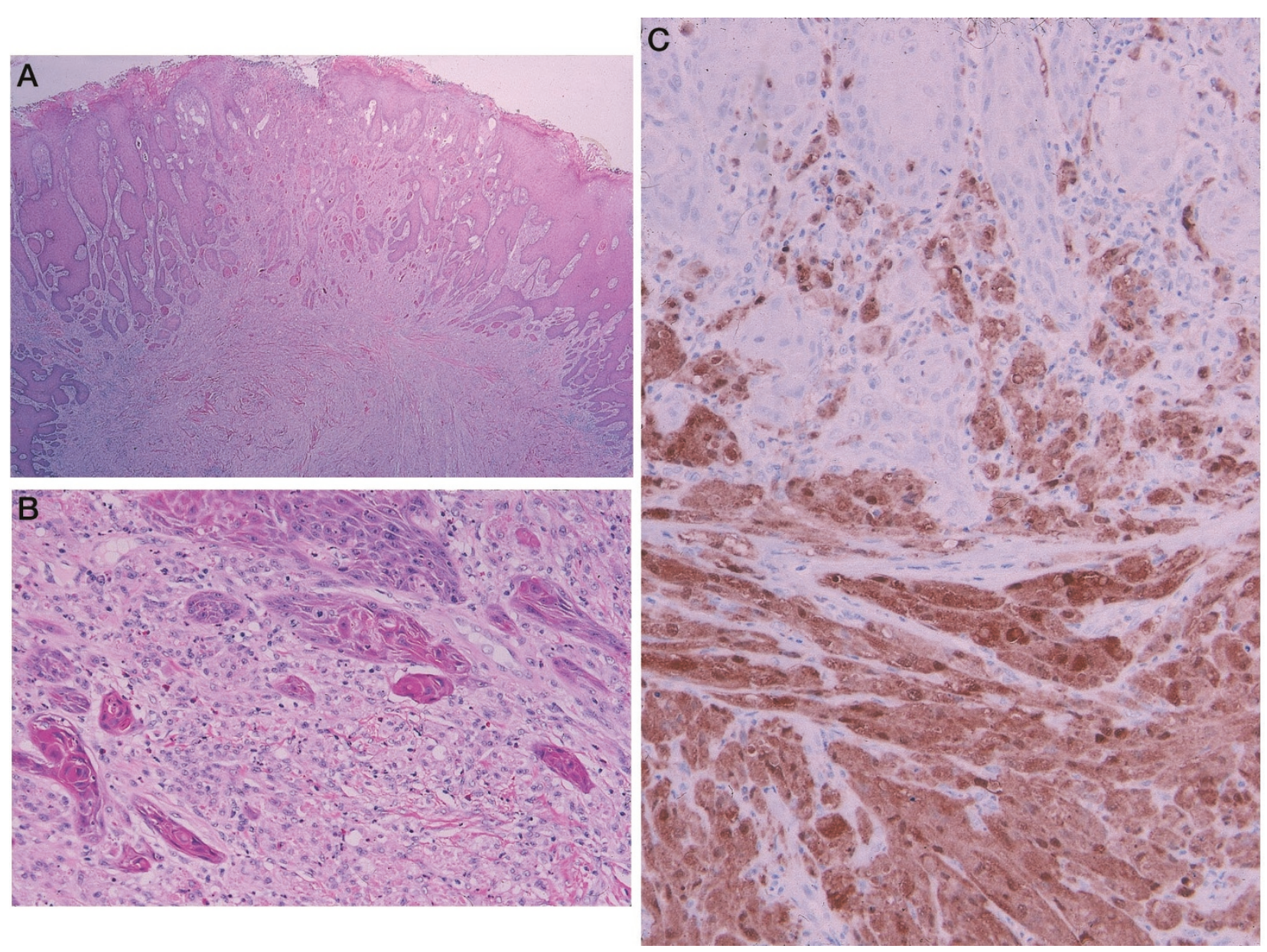

FIGURE 7. Laryngeal granular cell tumor (GCT) with pseudoepitheliomatous hyperplasia (PEH). A, B, marked PEH simulating the appearance of invasive squamous cell carcinoma. B, the granular cells can be seen in and around the squamous nests. C, GCT is intensely S100 protein immunoreactive. Note in Panels $\mathbf{A}$ and $\mathbf{C}$ that the PEH does not extend below the depth of the GCT.

at the angle of the mandible, bilaterally, in close association with the buccal nerve near the buccotemporalis fascia. Given the proximity to nerves, these nonneoplastic epithelial structures may be confused with carcinomatous invasion of nerves. This is especially the case during intraoperative consultation in a patient with known oral SCC. The JOC are typically not grossly visualized but may be sampled and sent for frozen section. Histologically, the JOC is composed of well-defined clusters of epithelial cells that may show the presence of intercellular bridges and palisading nuclei (Fig. 10). The cells are cytologically bland, lacking pleomorphism or mitotic activity. Keratinization is typically absent despite the presence of intercellular bridges.

Radiation-related changes and the differentiation of radiation-induced epithelial changes from recurrent/persistent SCC present one of the more challenging diagnostic dilemmas even for the most experienced surgical pathologist. This differentiation cannot always be achieved by conventional light microscopy, and unfortunately, there are no ad- junct modalities that may assist in remedying this diagnostic conundrum. Helpful features that may suggest radiation alterations of benign epithelium include the presence of secondary epithelial and stromal alterations associated with radiation injury, including smudged-appearing nuclei, stromal fibrosis with atypical stromal cells, and endothelial cell atypia (Fig. 11).

\section{Histologic Prognostic Indicators}

Among the histologic findings that may impact the prognosis in HNSCC are the following: (1) status of the surgical resection margins; (2) tumor size and thickness and location of the lesion; (3) pattern of invasion; (4) involvement of lymph-vascular spaces; (5) invasion of soft tissue structures, including nerves, bone, and cartilage; (6) nodal metastasis with or without extranodal extension of tumor; (7) distant metastasis; (8) host response; (9) neovascularization; and (10) presence of multiple malignancies $(10,37,38)$. DNA analysis and oncogene expression (e.g., p53, cyclin D1 protein) have been 

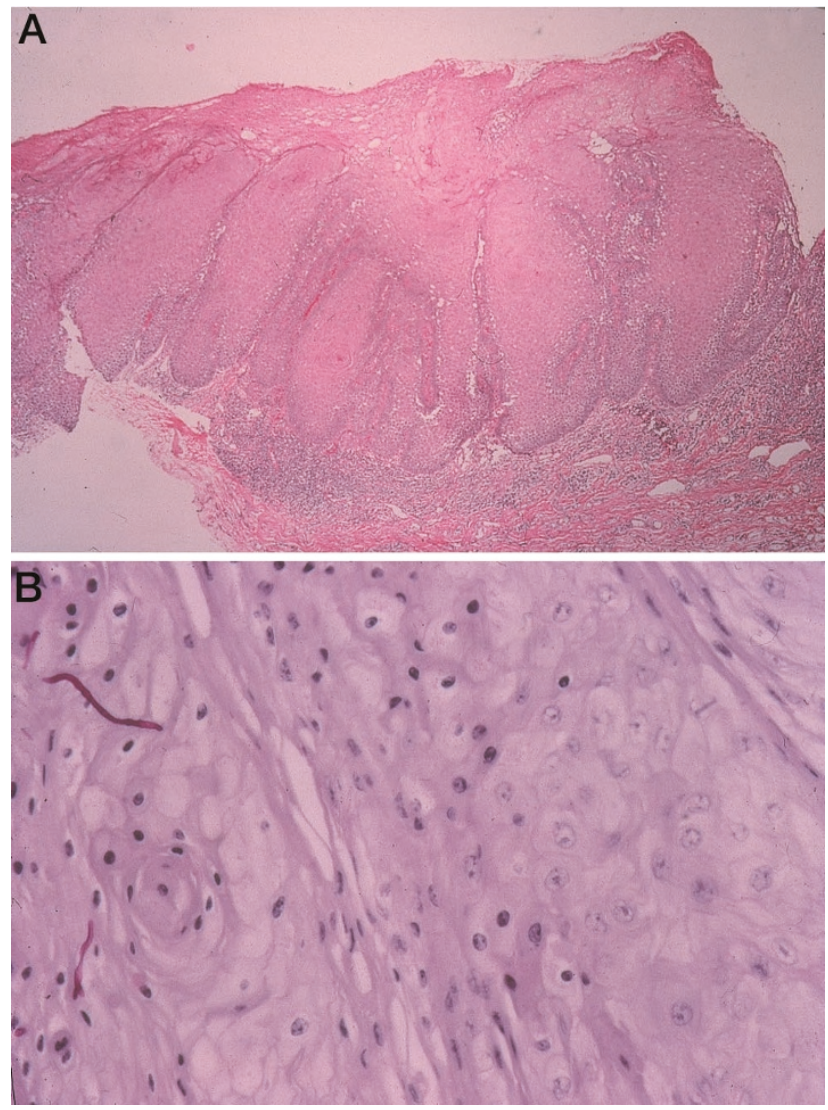

FIGURE 8. A, pseudoepitheliomatous hyperplasia of the larynx resulting from fungal (Candida) infection. B, periodic acid-Schiff staining shows intraepithelial fungal hyphae.

reported to have prognostic import in HNSCC $(39-42)$.

\section{Morphologic Subtypes of SCC}

\section{Papillary (Exophytic) SCC}

Papillary (exophytic) SCC represents an uncommon but distinct subtype of head and neck SCC (43-45). The demographics for this subtype of SCC are similar to those of conventional SCC, with the tendency to affect men more than women and to occur in adults, with a mean age in the 7 th decade of life. Papillary SCCs predilect to the larynx, oral cavity, oro- and hypopharynx, and sinonasal tract (43-45). The larynx is the most common site of occurrence. Symptoms vary according to the site of involvement. Papillary SCC usually arise de novo without identification of coexisting benign lesion such as a papilloma, although association with precursor papilloma or occurrence in patients with previous history of a papilloma at the site of the papillary SCC has been reported (45). Human papillomavirus (HPV) by in situ hybridization and polymerase chain reaction have been detected in papillary SCC (45).
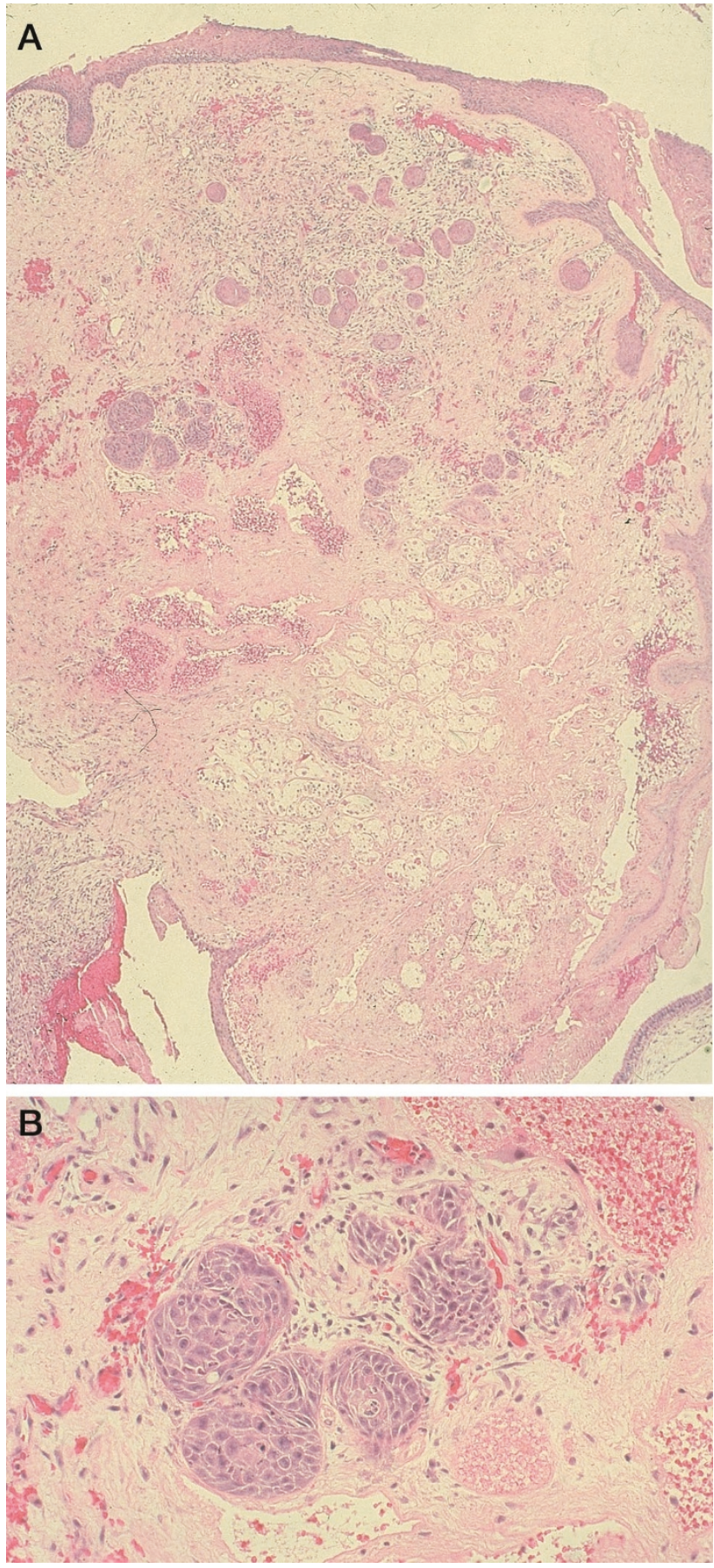

FIGURE 9. Necrotizing sialometaplasia (NS). A, preservation of the lobular architecture of the minor salivary glands is seen with foci of lobular necrosis. $\mathbf{B}$, the histologic hallmark is squamous metaplasia of residual acinar and ductal elements, in which the metaplastic lobules have smooth edges.

\section{Pathology}

Papillary SCC is most often seen as a solitary lesion with an exophytic or papillary growth. Tumor size may range from $2 \mathrm{~mm}$ up to $4 \mathrm{~cm}$. Histologically, papillary SCC has filiform growth with fingerlike projections and identifiable fibrovascular cores or a broad-based bulbous to exophytic growth with rounded projections resembling a cauliflower-like 


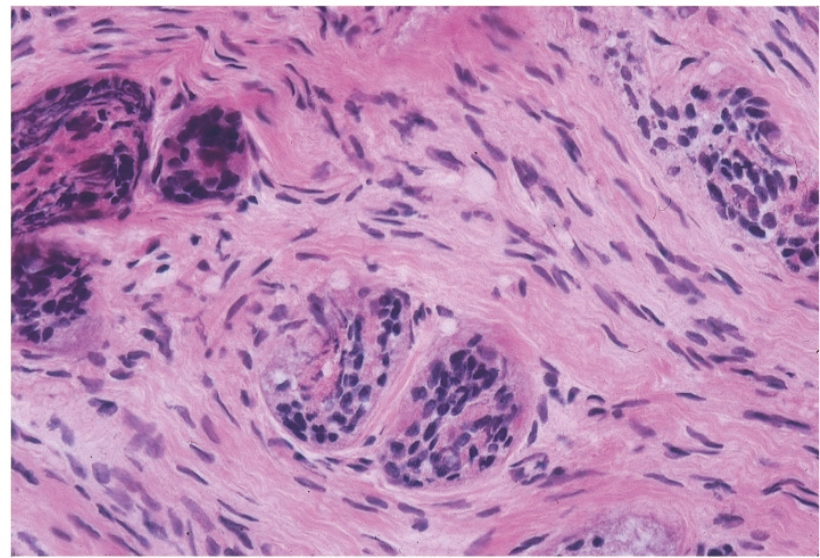

FIGURE 10. Juxtaoral organ of Chievitz is composed of well-defined clusters of cytologically bland epithelial cells lacking pleomorphism or mitotic activity. Note the close association with a nerve, which may be confused with carcinomatous invasion of the nerve.

growth pattern, in which fibrovascular cores can be seen but tend to be limited to absent (Fig. 12). The squamous epithelium is cytologically malignant, and this malignant epithelium identifies these tumors as carcinomas, separating them from papillomas. Surface keratinization is generally limited and often absent. Definitive invasion may be difficult to demonstrate in biopsy specimens, with the carcinomatous epithelium suggesting an in situ process rather than invasive carcinoma. However, the extent of growth with the formation of a clinically appreciable exophytic mass goes beyond the general concept of an in situ carcinoma. These tumors should be considered as invasive, even in the absence of definitive stromal invasion.

\section{Treatment and Prognosis}

Surgery is the treatment of choice; adjunctive therapy may be used. The majority of papillary SCCs are low clinical stage (T2); their behavior overall is similar to that of conventional SCC of similar stage (45), although some authors report a better overall prognosis for papillary SCC than for conventional SCC when matched for T stage (44).

\section{Differential Diagnosis}

The differential diagnosis of papillary SCC includes laryngeal papillomatosis (LP), conventional SCC, and VC. LP is distinguished by its bland epithelial proliferation. Cytologic abnormalities may be seen in LP; they tend to be focal when present but do not approach the level of dysplasia seen in papillary SCC. VC is characterized by a verrucous growth pattern with marked keratosis in layers or tiers, absent nuclear atypia, absent mitotic activity beyond the basal layer, and a pushing rather than infiltrative pattern of invasion. These features contrast with those seen in papillary and exophytic SCC.
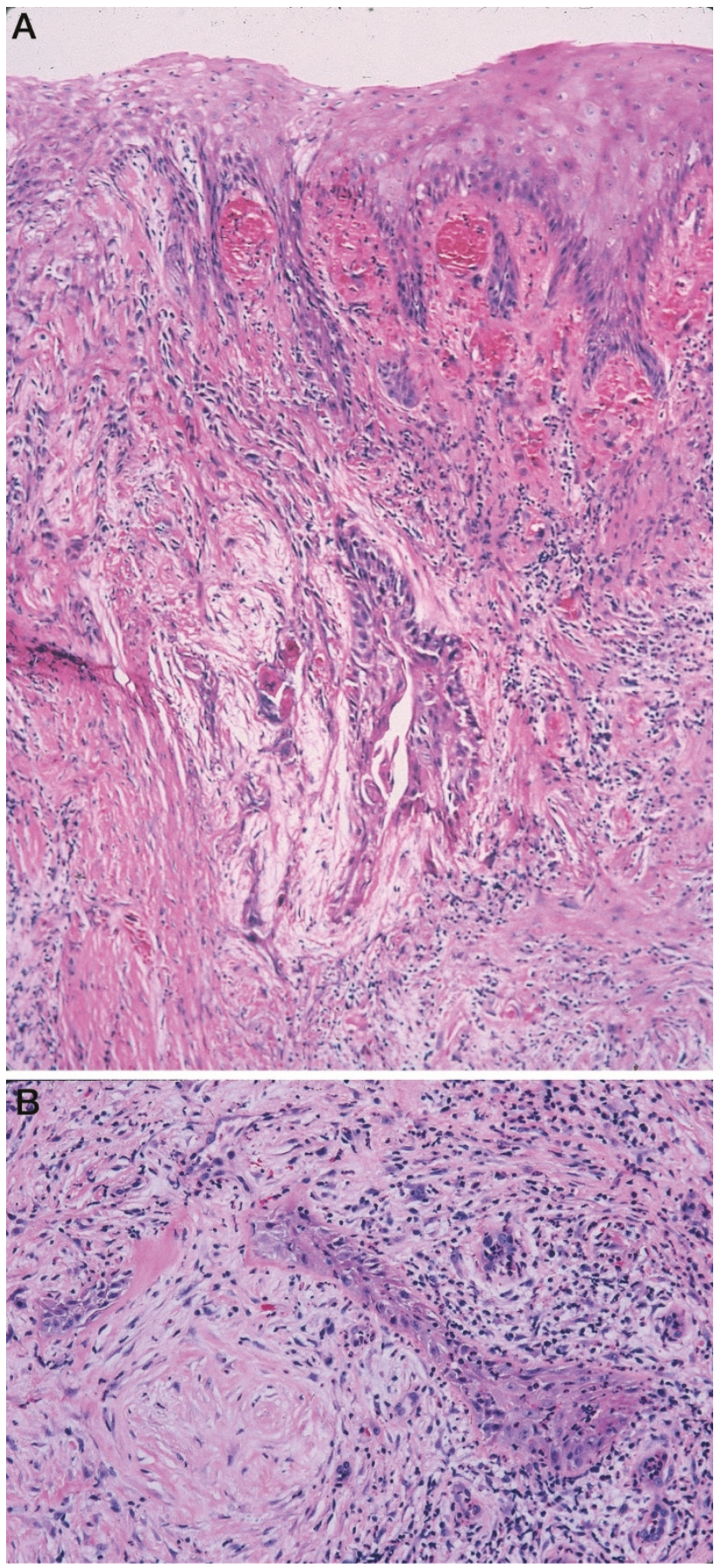

FIGURE 11. Radiation-related changes of the UADT. A, epithelial nest in the submucosa with surrounding stromal reaction suggest the presence of persistent or recurrent squamous cell carcinoma. B, helpful features that may suggest radiation alterations include the presence of secondary epithelial and stromal alterations associated with radiation injury such as smudged-appearing nuclei, stromal fibrosis with atypical stromal cells, and endothelial cell atypia.

\section{Verrucous Carcinoma}

VC is a highly differentiated variant of SCC with locally destructive but not metastatic capabilities. VC affects men more than women and generally occurs in the 6th and 7th decades of life. VC can occur anywhere in the upper aerodigestive tract. 

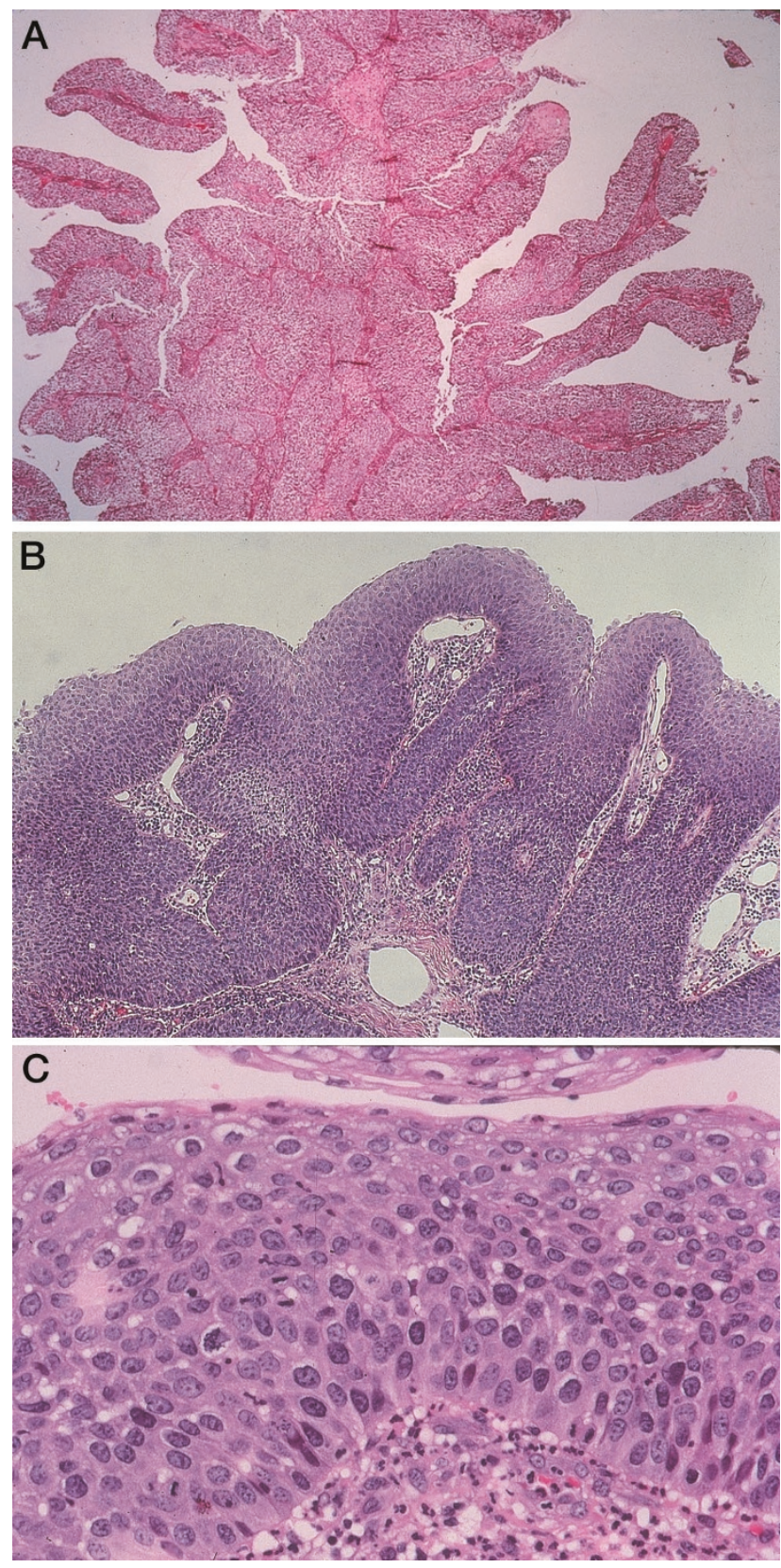

FIGURE 12. Laryngeal papillary squamous cell carcinoma. A, filiform growth with finger-like projections and identifiable fibrovascular cores. B, broad-based bulbous to exophytic growth with rounded projections resembling a cauliflower-like growth pattern with fibrovascular cores. C, the squamous epithelium is cytologically malignant.

The most common sites of occurrence in descending order include oral cavity, larynx, nasal fossa, sinonasal tract, and nasopharynx (46-49). Symptoms vary according to site: in the larynx, hoarseness is the most common complaint, whereas less frequent symptoms include airway obstruction, hemoptysis, dysphagia; in the oral cavity, there may be a mass with or without pain; in the sinonasal tract, there may be airway obstruction; in the nasopharynx, there may be dysphagia. The most common site of occurrence in the larynx is the glottic area. Oral cavity VCs most commonly arise on the buccal mucosa and gingiva.

The etiology of VC is still being speculated and includes tobacco smoking or chewing. Viral induction appears to be a legitimate etiologic factor in the development of VC, but a causal relationship has not been clearly identified. The active role of HPV is more likely as a promoter in the multistep process of carcinogenesis in squamous cells of the upper aerodigestive tract (see later under "Viruses").

\section{Pathology}

VCs appear as tan or white, warty, fungating or exophytic, firm to hard masses of varying size measuring up to 9-10 $\mathrm{cm}$ in diameter. In general, the tumors are attached by a broad base. The histologic appearance of $\mathrm{VC}$ is that of a benign-appearing squamous cell proliferation requiring the following characteristics for diagnosis: (1) uniform cells without dysplastic features nor mitoses; (2) marked surface (ortho)keratinization ('church-spire' keratosis); and (3) broad or bulbous rete pegs with a pushing but not an infiltrative margin (Fig. 13). A mixed chronic inflammatory cell infiltrate composed of lymphocytes, plasma cells, and histiocytes may be prominent along the adjacent stroma. The pathologic diagnosis of VC may be extremely difficult, requiring multiple biopsies over several years before identification of diagnostic features supporting appropriate interpretation. Both clinicians and pathologists should be aware of this fact. To this end, adequate biopsy material is critical to interpretation and should include a good epithelialstromal interface. The pathologist should not overinterpret a verrucoid lesion as a carcinoma without seeing the relationship of the more superficial aspects of the lesion to the underlying stroma.

\section{Treatment and Prognosis}

Surgery (conservation or total laryngectomy) is the definitive diagnostic modality. The literature supports the dogma that radiotherapy is contraindicated in the treatment of VC. The reason for this is the purported induction of anaplastic transformation of VC after radiotherapy. However, similar transformations can occur after surgery, cryosurgery, and even without any treatment. Therefore, radiotherapy is not contraindicated in the treatment of VC and can be used in selected clinical settings, including with those patients with advanced disease or patients who are not good surgical candidates. Metastatic tumor to regional lymph nodes is rare, and distant metastases do not occur. The prognosis is excellent after complete surgical removal. Local recurrence may occur if incompletely excised. Cervical adenopathy may be associated with $\mathrm{VC}$, representing reactive changes and not metastatic disease. 

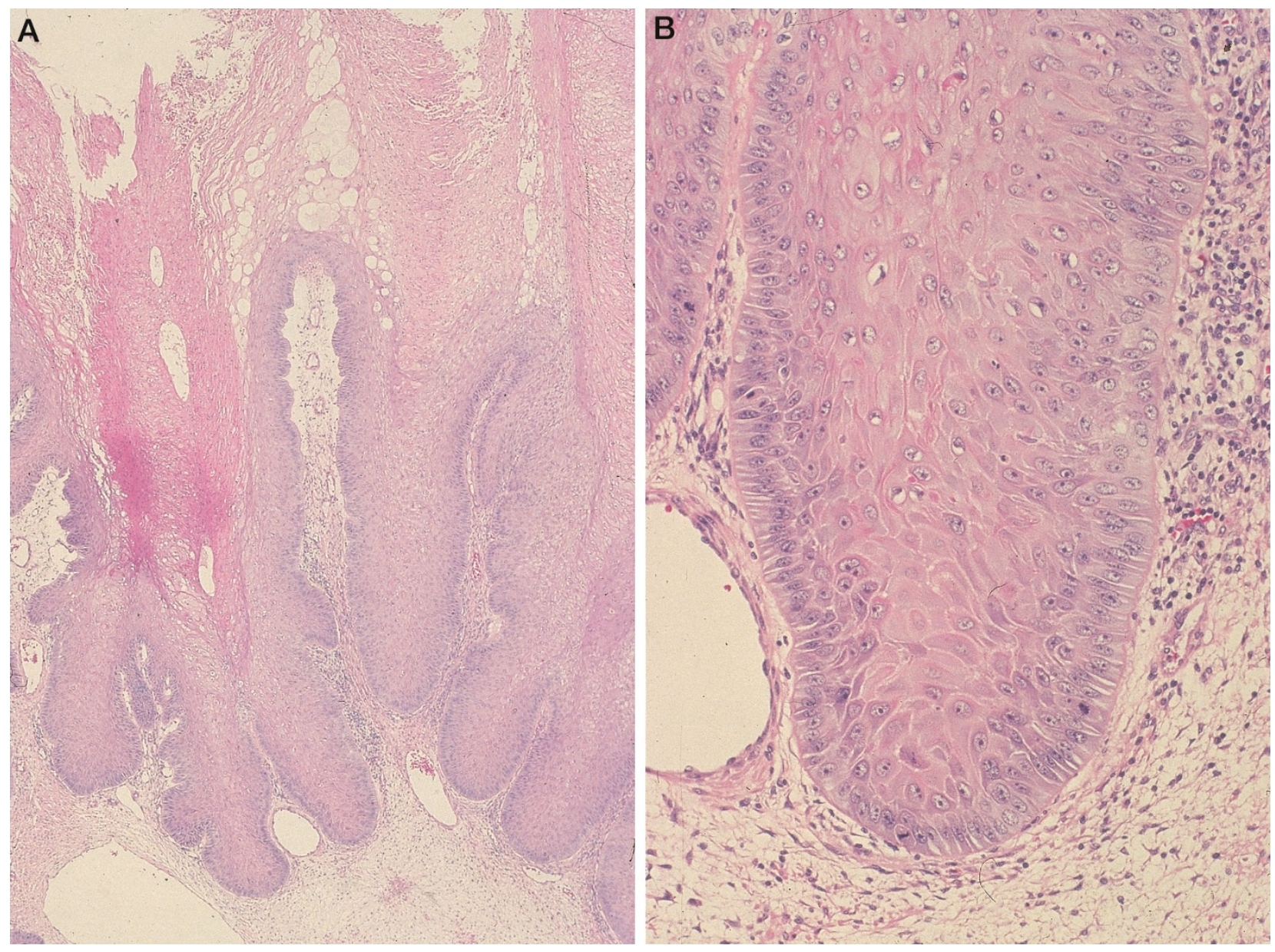

FIGURE 13. Laryngeal verrucous carcinoma (VC). A, squamous cell proliferation with marked surface keratinization ('church-spire' keratosis) and broad or bulbous rete pegs pushing downward into the subjacent stroma. B, VC is characterized by bland, uniform cells showing maturation, retention of polarity, no dysplasia nor nuclear pleomorphism, absence of increased nuclear-to-cytoplasmic ratio, and absence of dyskeratosis.

\section{Differential Diagnosis}

The pathologic diagnosis of VC may be extremely difficult, requiring multiple biopsies over several years before identification of diagnostic features supporting appropriate interpretation. Both clinician and pathologists should be aware of this fact. To this end, adequate biopsy material is critical to interpretation and should include a good epithelial-stromal interface. The pathologist should not overinterpret a verrucoid lesion as a carcinoma without seeing the relationship to the underlying stroma.

The differential diagnosis of VC includes a variety of lesions, including reactive keratosis, epithelial hyperplasia or pseudoepitheliomatous hyperplasia; verruca vulgaris; (keratotic) squamous papilloma or papillomatosis; Schneiderian papillomas; and keratoacanthoma (when VC affects cutaneous sites). However, VC must be differentiated from the 'conventional' type of SCC. The differentiation of VC from a 'conventional' type of carcinoma is based on the presence or absence of cytologic abnormalities. Dysplastic features limited in scope and confined to the basal zone areas can be seen in VC. Any dysplastic features greater than this should exclude a diagnosis of VC. Hybrid neoplasms composed of VC and coexisting conventional SCC occur $(48,49)$ and have been reported in up to $20 \%$ of cases (48). Careful evaluation of the depth of the lesion is important to exclude this possibility.

Proliferative verrucous leukoplakia (PVL) and verrucous hyperplasia represent interrelated and irreversible mucosal lesions of the oral cavity and upper aerodigestive tract, with a propensity to progress to either VC or conventional types of SCC (50-52). PVL is a rare aggressive form of oral leukoplakia with a tendency to recur, often with multifocal oral involvement, and to undergo malignant transformation. PVL is most common in elderly women (mean age in the 8th decade of life) with a long history (decades) of oral leukoplakia. PVL most commonly begins on the buccal mucosa followed by the hard and soft palate, alveolar mucosa, tongue, floor of mouth, gingiva, and lip. Although a history of tobacco use is present in a high percentage of patients $(>50 \%)$, a significant minority of 
patients have no history of tobacco use. The diagnosis of PVL in its early stages is virtually impossible because of the innocuous appearance of the lesions. The clinical and pathologic appearance in the early stages of PVL is no different than any other type of leukoplakic lesion. Clinically, the lesion is a flat, thickened keratosis with the histologic appearance of a nondysplastic keratosis. With progression of disease, the lesions become multiple, multifocal, and confluent, with an exophytic and/or warty (verrucoid) appearance. It is in the latter clinical form that squamous cancer (VC or conventional SCC) is seen. Any given lesion may show a combination of verrucous hyperplasia, $\mathrm{VC}$, and conventional welldifferentiated SCC. Given the fact that PVL is associated with VC in a high percentage of cases, some authors believe that PVL should be considered to be a premalignant condition or an early biologic form of VC $(51,53)$. This would then obviate the confusion, both clinically and pathologically, that surrounds the use of the term verrucous hyperplasia in describing these oral cavity lesions. PVL is composed of hyperplastic squamous epithelium with regularly spaced, verrucous epithelial projections and associated hyperkeratosis. PVL is a sharply defined lesion, and in contrast to the downward growth into the underlying submucosal compartment by the bulbous rete pegs in VC, the hyperplastic epithelium in PVL remains superficial (without submucosal invasion) and does not extend deeper than that of the adjacent epithelium (Fig. 14). This raises the issue of adequate sampling and the difficulties of differential diagnosis on incisional biopsy material. To exclude the presence of submucosal invasion, complete excision of the lesion, allowing for histologic examination of the entire lesion is most appropriate. The treatment of PVL is by surgical excision. However, disease-free survival rates after surgery are low due to recurrence and multifocal involvement. Radiotherapy has not been shown to be effective in controlling disease.

Rarely, verruca vulgaris (VV) may occur in the larynx and present difficulties in differentiation from VC. In VV, there is a prominent keratohyaline granular layer, parakeratosis, and sharp acanthotic pegs, features not present in VC (54).

\section{Spindle Cell Squamous Carcinoma}

Spindle cell squamous carcinoma (SCSC) is defined as a tumor composed of conventional SCC (in situ or invasive carcinoma) associated with a malignant spindle cell stromal component. Synonyms include 'sarcomatoid' carcinoma, carcinosarcoma, pleomorphic carcinoma, metaplastic carcinoma, collision tumor, pseudosarcoma, and Lane tumor.

The overwhelming majority of SCSC occur in men (85\%), most frequently in the 6th-8th decades of life. SCSC can occur anywhere in the upper aerodigestive tract. The most common sites, in descending order of occurrence, include the larynx (true vocal cords $>$ false vocal cords and supraglottis), oral cavity (lips, tongue, gingiva, floor of mouth, buccal mucosa), skin, tonsil, and pharynx. Symptoms vary according to site: in the larynx, there may be hoarseness, voice changes, airway obstruction, dysphagia; in the oral cavity or skin, there may be a mass or nonhealing sore with or without pain; in the sinonasal tract and nasopharynx, there may be airway obstruction, pain, epistaxis, discharge, facial deformity, unilateral otitis media, or orbital symptoms. There is no specific correlation with known risk factors (alcohol, tobacco, or environment/occupation). SCSC has been reported in areas of prior irradiation.

\section{Pathology}

SCSC often is a grossly polypoid or fungating mass commonly found in the larynx, hypopharynx, oral cavity, and sinonasal tract (55). Variations in the gross appearance may correlate with the primary site of occurrence: in the larynx, polypoid or exophytic; in sinonasal/nasopharynx, fungating and/or ulcerative. SCSC are firm, tan-white, gray or pink masses varying in size from 1 to $6 \mathrm{~cm}$.

The histologic features that define SCSC include the identification of a malignant undifferentiated spindle cell proliferation and the presence of a conventional squamous cell component (Fig. 15). The latter includes either in situ squamous carcinoma or frankly invasive differentiated squamous carcinoma. The spindle cell component generally is the dominant cell type. The spindle cell proliferation is usually hypercellular and pleomorphic with large, hyperchromatic nuclei, prominent nucleoli, and many mitoses (typical and atypical). Necrosis is not uncommon. The spindle cell proliferation may be sparsely cellular (hypocellular), with marked stromal collagenization (so-called collagenized SCSC), but nuclear pleomorphism and mitotic figures are still present (Fig. 16). The growth pattern varies and includes fascicular, storiform, or palisading; an associated myxomatous stroma may be present. Heterologous elements, including bone and cartilage, may be present and may even be malignant (chondrosarcomatous or osteosarcomatous foci).

The spindle cells are cytokeratin immunoreactive in the majority of cases (56-60) but in up to $40 \%$ of cases may be cytokeratin negative (57). Cytokeratin staining may vary from focal to diffuse. Expression of vimentin and various myogenic markers (desmin, actins) have been reported (58-61). S100 protein and HMB-45 are negative. Ultrastructurally, in the majority of cases, SCSC show evidence of epithelial derivation, including desmosomes, tonofilaments, and macula adherens $(56,62)$. The his- 


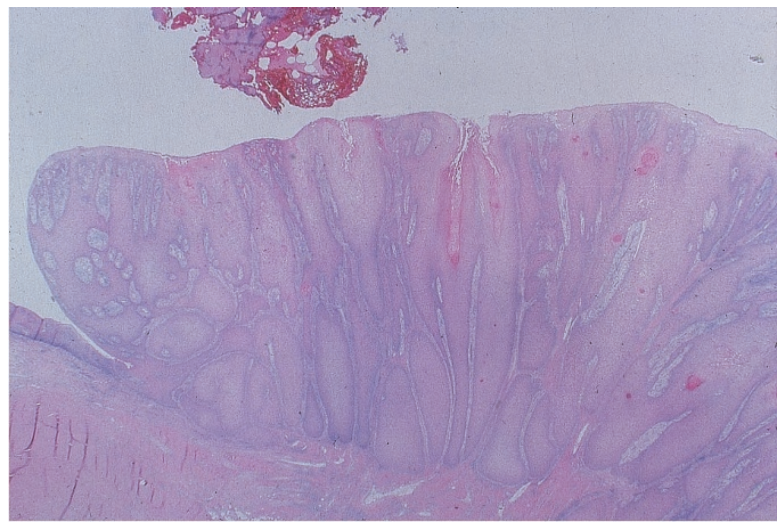

FIGURE 14. Proliferative verrucoid leukoplakia (PVL). This oral cavity lesion shows morphologic similarities to verrucous carcinoma. Note the hyperplastic epithelium in PVL remains superficial (without submucosal invasion) and does not extend deeper than that of the adjacent epithelium (extreme left).
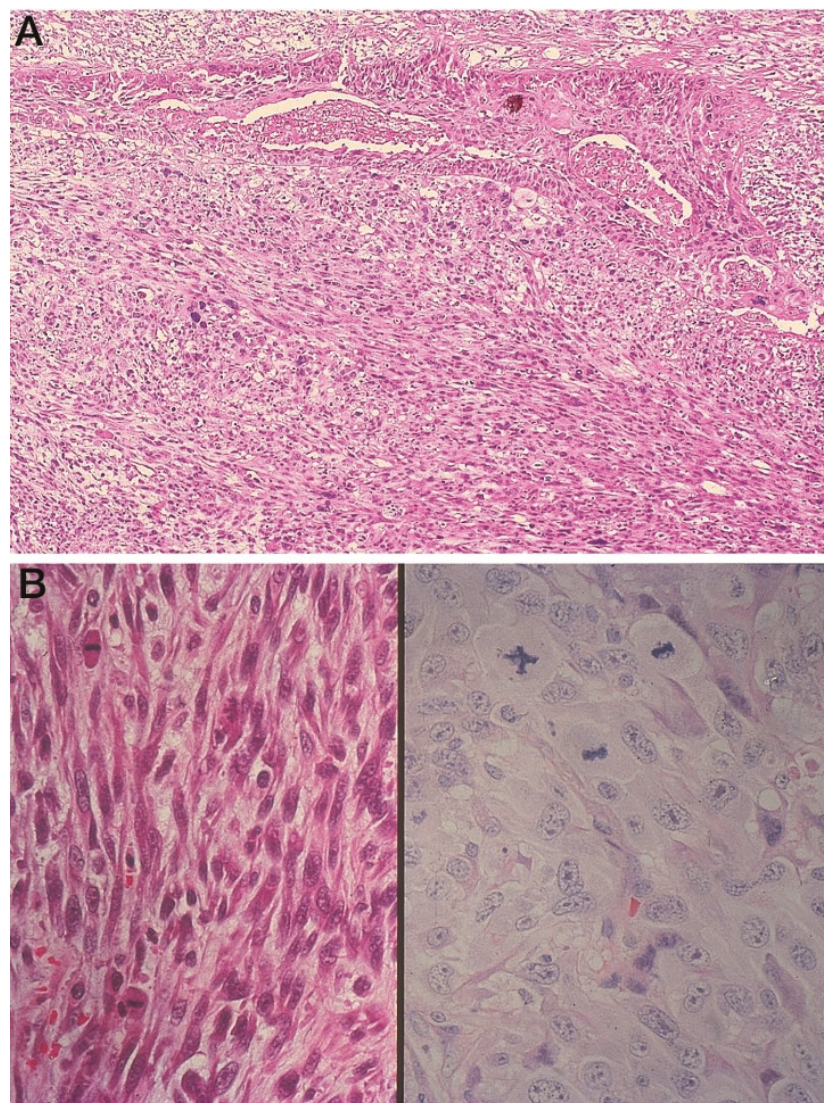

FIGURE 15. A, laryngeal spindle cell squamous carcinoma showing a differentiated squamous cell carcinoma (top) associated with a malignant (undifferentiated) spindle cell proliferation. $\mathbf{B}$, the malignant cell component of spindle cell squamous carcinoma may include (left) spindle-shaped cells and (right) epithelioid cells. Increased mitoses, including atypical forms, are seen.

togenesis of the spindle cells is controversial, as evidenced by the array of names given to this tumor.

Epithelial derivation is supported by the intimate association with conventional SCC and by the presence of cytokeratin immunoreactivity in the majority of cases and lack of immunoreactivity with other
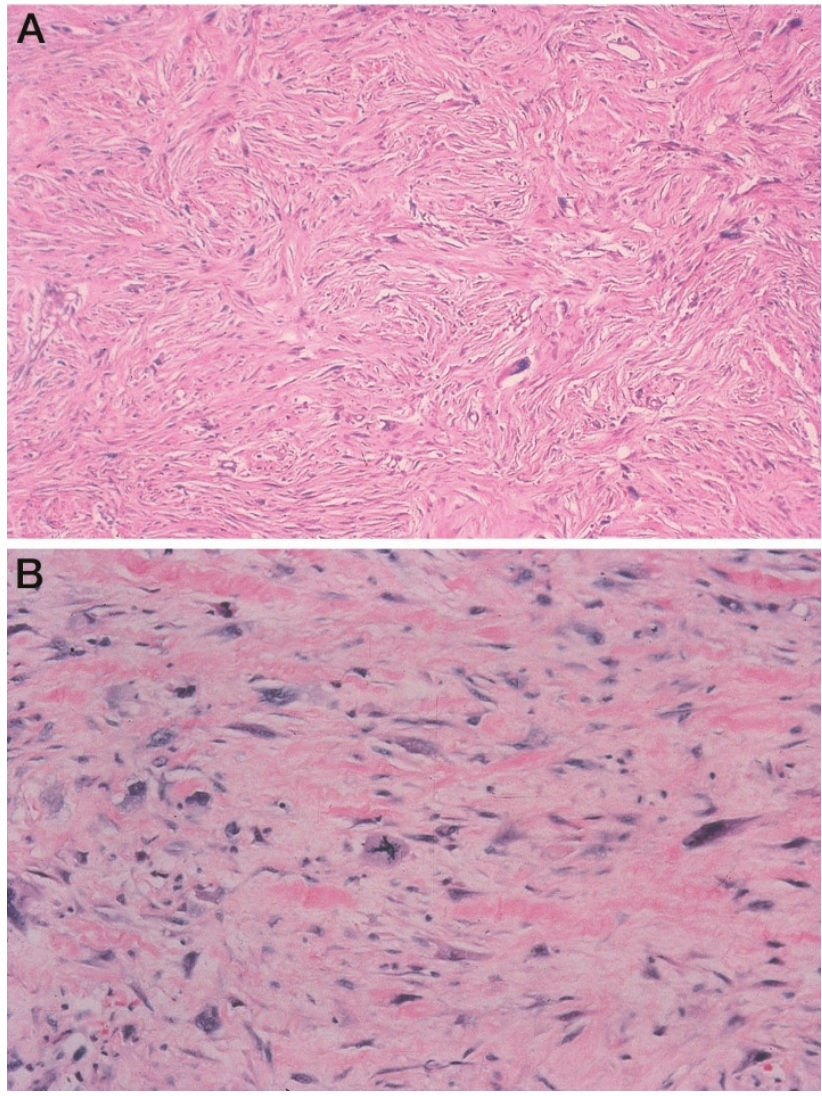

FIGURE 16. A, B, Hypocellular, collagen-rich spindle cell squamous carcinoma. Despite the limited cellularity, there is nuclear pleomorphism and atypical mitoses, defining this lesion as a malignancy.

antibodies. Despite the presence of heterologous elements, including malignant bone or cartilage, neither of these components has been reported to metastasize, and in all probability, they represent a metaplastic phenomenon. Identical immunohistochemical p53 expression patterns in the epithelial and spindle cell components of SCSC support the concept that these phenotypically divergent cell populations share similar developmental pathways and divest the concept that SCSC represents a reactive process or a collision tumor between epithelial and mesenchymal components (63).

\section{Treatment and Prognosis}

Surgery is the preferred therapy. Radiotherapy may be used as an adjunct to surgery, but neither radiotherapy nor chemotherapy has merit as the sole therapeutic modality. The prognosis is dependent on the clinical stage but, in general, is considered poor. Polypoid lesions may behave less aggressively than flat, ulcerative tumors, perhaps correlating with limited (superficial) invasion. Vocal cord lesions that manifest symptoms early in the disease course may have a better prognosis than SCSC arising in other sites (supraglottis, hypo- and nasopharynx), where symptoms occur only after 
the tumor has become large and extensively infiltrative. Metastatic disease primarily occurs to cervical lymph nodes and lung and may include the following: (1) conventional SCC alone, (2) spindle cell carcinoma alone, or (3) both conventional and spindle cell squamous carcinoma.

\section{Differential Diagnosis}

The squamous cell component of SCSC may be limited, requiring multiple sectioning for identification, or it may be absent. The differential diagnosis includes the following: reactive myo- or fibroblastic proliferations, mucosal malignant melanoma, and sarcomas including malignant fibrous histiocytoma, fibrosarcoma, malignant peripheral nerve sheath neoplasm, osteosarcoma, and chondrosarcoma. These sarcomas, although uncommon in relation to a mucosal surface of the head and neck region, do occur. In general, these tumors are deeply seated in any given location and do not usually result in a polypoid mass protruding from a mucosal surface. As a rule, in the absence of any other confirmatory studies (i.e., immunohistochemistry, electron microscopy), a malignant spindle cell neoplasm of a mucosal surface of the upper aerodigestive tract, presenting as a polypoid lesion or identified in more superficial locations of the submucosa, should be considered an SCSC. This is true even in the absence of a squamous carcinomatous component, in the presence of heterologous matrix-producing elements, or in the absence of cytokeratin immunoreactivity.

Reactive and neoplastic lesions composed of myofibroblastic cells include nodular fasciitis-like lesions and inflammatory myofibroblastic tumors (IMT) and have been reported as occurring in the larynx (64) These lesions are moderately cellular with a proliferation of spindle-shaped cells but do not display a striking degree of nuclear pleomorphism. Mitotic figures may be encountered, but atypical mitoses are not seen. The findings of atypical mitoses should prompt consideration of a true malignancy. Although the lesions are not encapsulated, they do not exhibit the insidious pattern of infiltration of adjacent tissues that is characteristic of more aggressive lesions. The lesions may fill the submucosal region, abutting the basement membrane on which the mucosal epithelial cells are resting; however, the spindle cell proliferation does not infiltrate into the mucosal epithelial cells. Nevertheless, the overlying mucosa may appear atrophic in areas. These lesions are cytokeratin negative. In addition, the myofibroblastic cell component may be positive for muscle-specific actin (HHF35), smooth muscle actin, and vimentin. Recent evidence has shown the presence of anaplastic lymphoma kinase $(A L K)$ gene rearrangements and expression in IMT, indicating oncogenic ALK expression as an important mech- anism in the pathogenesis of IMT and supporting the concept that IMTs are neoplastic $(65,66)$

\section{Basaloid SCC}

Basaloid SCC (BSCC) is a high-grade variant of SCC with a predilection to the base of tongue, supraglottic larynx, hypopharynx, and palatine tonsil $(67,68)$ BSCC is histologically characterized by an invasive neoplasm composed of basaloid cells intimately associated with a dysplastic squamous epithelium, in situ SCC, and/or invasive SCC.

BSCC occurs more commonly in men than in women and predominantly occurs in the 6 th -7 th decades of life. These tumors have a predilection for the hypopharynx (pyriform sinus), larynx (supraglottis), and tongue. Symptoms depend on the site of occurrence and include hoarseness, dysphagia, pain, or a neck mass. Etiologic factors include excessive alcohol and/or tobacco use. The cell of origin has not definitively been identified but in all probability is a single totipotential cell capable of divergent differentiation and located either in the basal cell layer of the surface epithelium or within seromucous glands.

\section{Pathology}

Grossly, these tumors are described as firm to hard, tan-white masses, often with associated central necrosis measuring up to $6.0 \mathrm{~cm}$ in greatest dimension. Infrequently, they may be exophytic in appearance. Histologically, BSCC is an invasive neoplasm composed of basaloid cells with an associated squamous component and demonstrating a variety of growth patterns, including solid, lobular, cribriform, cords, trabeculae, and glandlike or cystic growth (Fig. 17). The basaloid cell component is the predominant cell type and consists of cells with pleomorphic, hyperchromatic nuclei, scanty cytoplasm, and increased mitotic activity. Peripheral nuclear palisading may be present. Comedonecrosis is seen in the center of the neoplastic lobules. Intercellular deposition of a hyalin or mucohyalin material can be seen, similar in appearance to the reduplicated basement membrane material that is seen in some salivary gland tumors (Fig. 17). Infrequently, a spindle cell component may be identified, and true neural-type rosettes may rarely be present (69). The squamous component includes dysplastic squamous epithelium, foci of abrupt keratinization, in situ SCC, or invasive SCC. The squamous foci typically are a minor component, may be focally present, and may be absent in biopsies. Continuity with the surface epithelium may be seen.

Histochemical stains may show periodic acidSchiff-positive and Alcian blue-positive material within the cystic spaces. Immunoreactivity is con- 

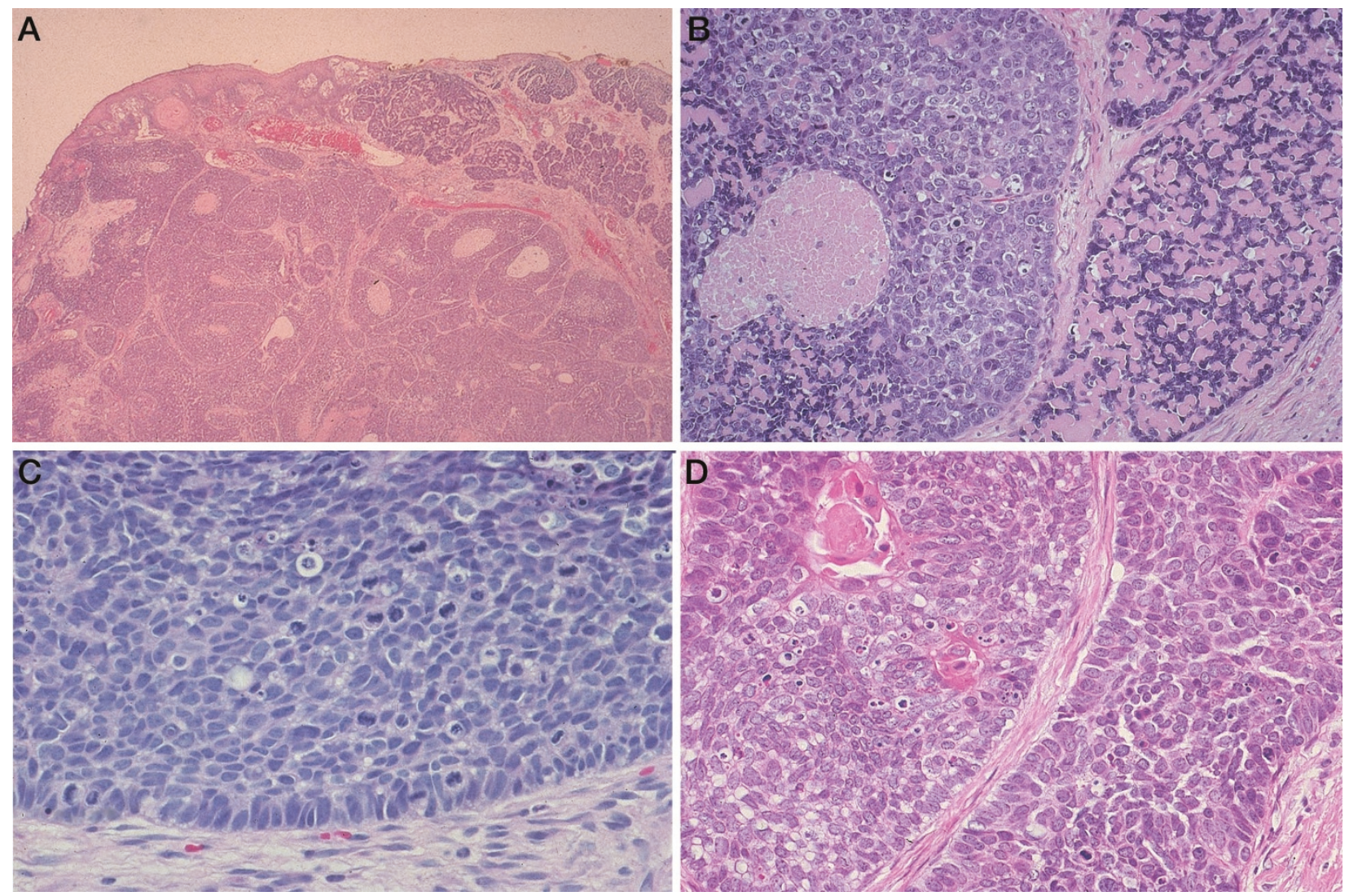

FIGURE 17. Basaloid squamous cell carcinoma. A, infiltrating tumor arising in continuity with the surface epithelium arranged in a variety of growth patterns, including lobular (solid) and cord-like patterns. B, central comedotype necrosis can be seen within the lobules of infiltrating carcinoma (left); intercellular deposition of eosinophilic hyalin or mucohyalin material that may simulate the appearance of reduplicated basement membrane material associated with tumors of salivary gland origin can be seen in between the neoplastic cords (right). C, basaloid-appearing cells showing marked pleomorphism, hyperchromatic nuclei, scanty cytoplasm, and increased mitotic activity. Note the presence of peripheral nuclear palisading. D, the squamous cell component is focally seen in the form of keratinization.

sistently present with epithelial markers, including cytokeratins (AE1/3, 34 $\beta$ E12,CAM5.2), EMA, and CEA (68-70). Neuroendocrine markers (i.e., chromogranin and synaptophysin) and HMB-45 are negative. BSCC may express NSE but is considered nonspecific. Variable expression can be seen with vimentin, S-100 protein, and actin. EM shows the features of SCC, including cell groups with numerous and prominent tonofilament bundles, increased desmosomes, and epithelial pearls and loose stellate granules or replicated basal lamina within the cystic spaces $(67,71)$ and absence of glandular differentiation (71). Flow cytometry studies have shown that patients with BCSC whose tumors were DNA aneuploid had better mean survival periods than did those with diploid DNA tumors.

\section{Treatment and Prognosis}

The treatment of choice for BSCC includes radical surgical excision and, as a result of both early regional lymph node as well as distant visceral metastases, radical neck dissection and supplemental radio- and chemotherapy may be included in the initial management protocol. BSCC is an aggres- sive, high-grade tumor with increased tendency to be multifocal, deeply invasive, and metastatic. Metastases occur via lymphatics and blood vessels, with sites of predilection including regional and distant lymph nodes, lung, bone, skin, and brain. Metastases include both basaloid and squamous cell components. BSCC is a rapidly fatal neoplasm associated with high mortality rates within the first year after diagnosis.

\section{Differential Diagnosis}

Shallow biopsies may belie the depth and extent of invasion and may not be representative of the lesion leading to erroneous classification. The differential diagnosis of BSCC primarily includes adenoid cystic carcinoma and small cell (undifferentiated) neuroendocrine carcinoma. Adenoid cystic carcinoma is characterized by the presence of a proliferation of basaloid cells with homogenousappearing hyperchromatic nuclei lacking significant pleomorphism and generally devoid of mitotic activity. Further, squamous differentiation is not a component of adenoid cystic carcinoma. Small cell neuroendocrine carcinoma may be difficult to dif- 
ferentiate from BSCC by light microscopy. This is an important differentiation as small cell neuroendocrine carcinomas are nonsurgically treated with radiation and systemic chemotherapy. Morice and Ferreira (70) compared the immunoreactive profiles of BSCC from small cell neuroendocrine carcinoma and adenoid cystic carcinoma. These authors found that although rare examples of BSCC may be reactive with neuroendocrine markers, including chromogranin and synaptophysin, these markers are typically positive in small cell neuroendocrine carcinoma but absent in BSCC.

\section{Undifferentiated Carcinoma \\ (Lymphoepithelioma-Like or \\ Nasopharyngeal-Type)}

Undifferentiated carcinoma is a variant of SCC commonly of nasopharyngeal origin or Waldeyer's ring origin (i.e., base of tongue, palatine tonsils, and adenoids) that arises from the surface epithelium. According to the World Health Organization, nasopharyngeal carcinomas are divided into two histologic subtypes: keratinizing and nonkeratinizing (72). The nonkeratinizing type is further subdivided into nonkeratinizing differentiated and nonkeratinizing undifferentiated (Table 2). Synonyms for undifferentiated carcinoma include lymphoepithelioma; Rigaud and Schmincke types of lymphoepithelioma; and transitional carcinoma.

\section{Clinical}

Overall, NPC is an uncommon neoplasm in the United States, accounting for approximately $0.25 \%$ of all cancers. In China, it accounts for $18 \%$ of all cancers. NPC affects men more than women and occurs over a wide age range but is most common in the 6th decade of life. Irrespective of the histologic type the clinical presentation is similar and includes neck mass, hearing loss, nasal obstruction, nasal discharge, epistaxis, pain, otalgia, and headache. The signs and symptoms are often subtle and nonspecific, leading to delay in diagnosis and eventual presentation with advanced disease. The lateral wall of the nasopharynx (fossa of Rosenmüller) is the most common site of occurrence. Lymphoepithelioma-like carcinomas can be found in nonnasopharyngeal head and neck sites, including the larynx and hypopharynx (73, 74; see Table 1).

TABLE 2. World Health Organization (WHO) Classification of Nasopharyngeal Carcinoma

WHO Type I

Keratinizing squamous cell carcinoma

WHO Type II

Nonkeratinizing differentiated

Nonkeratinizing undifferentiated
The suggested etiologic factors include the following:

- Genetic and geographic: increased incidence in China, especially in southern (Kwantung province) and northern provinces and Taiwan; although the incidence among Chinese people decreases after emigration to low-incidence areas, it still remains higher than in nonChinese populations; HLA-A2 histocompatibility locus has been suggested as the marker for genetic susceptibility to nasopharyngeal carcinoma.

- Epstein-Barr virus (EBV): elevated titers of anti-EBV antibodies are associated with nasopharyngeal carcinoma (undifferentiated and nonkeratinizing types); (75) however, no clear cause and effect has been established between the presence of EBV and the development of nasopharyngeal carcinoma.

- Other suggested implicating factors: diet, poor hygiene, and environment.

Radiologic findings include the following. Plain film radiograph findings are variable and nonspecific, including a soft tissue mass, bone destruction, and sinus opacity; computed tomography may demonstrate bone invasion, including invasion of the base of skull and expansion of sinuses with progression of disease.

\section{Pathology}

The gross appearance of NPC varies from a mucosal bulge with an overlying intact epithelium to a clearly demonstrable mass with extensive involvement of the surface epithelium to a totally unidentifiable lesion fortuitously sampled and identified by microscopic evaluation. Three histologic types are identified based on the predominant appearance and include keratinizing, nonkeratinizing (Fig. 18), and undifferentiated (Fig. 19-21). For a description of the histologic features, see Table 3.

\section{Treatment and Prognosis}

As a result of the anatomic constraints imposed by the nasopharynx and the tendency of these neoplasms to present in an advanced stage, supervoltage radiotherapy (6500 to $>7000$ rads) is considered the treatment of choice. Responsiveness to radiation varies per histologic type and thereby affects prognosis. The keratinizing subtype is not radioresponsive. These tumors have a tendency to remain localized without (nodal) dissemination. However, based on the radioresistance, the 5-year survival rate is in the range of $10-20 \%$. The nonkeratinizing subtype is variably radioresponsive. These tumors have a tendency to metastasize to regional lymph nodes. Based on their relative radioresponsiveness, the 5-year survival rate is in the range of $35-50 \%$. The undifferentiated 

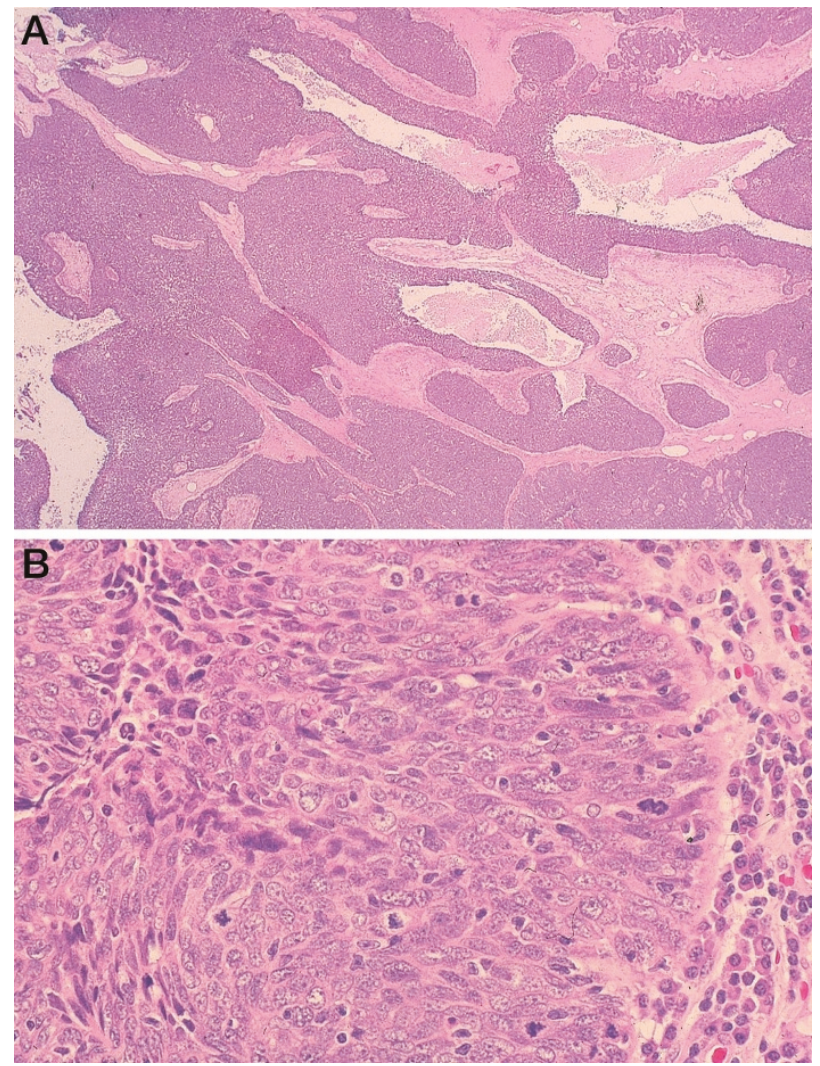

FIGURE 18. Nasopharyngeal nonkeratinizing carcinoma,

differentiated type. This carcinoma is characterized by the presence of interconnecting cords of neoplastic cells. $\mathbf{B}$, at higher magnification the cellular infiltrate of the nasopharyngeal nonkeratinizing carcinoma, differentiated type shows the absence of keratinization.

subtype is radiosensitive. These tumors have a tendency to metastasize to regional lymph nodes. Nevertheless, despite the tendency to disseminate and to be the least differentiated of all the subtypes, based on their radiosensitivity, the 5-year survival rate is approximately $60 \%$. Factors that may affect prognosis include the following: (1) clinical stage; (2) patient age (the younger the age the better the prognosis), which probably correlates to the fact that nasopharyngeal carcinoma occurring in younger patients is predominantly of the undifferentiated type; and (3) lymph node metastasis (positive nodes decreases survival by approximately $10-20 \%$ ). The sole use for chemotherapy is for widespread disease. The Regaud and Schmincke types of nasopharyngeal carcinoma indicate those neoplasms with syncytial versus individual cell invasive growth patterns, respectively; these designations and their correlated growth have no bearing on the biology of the disease.

\section{Differential Diagnosis}

The differential diagnosis of NPC includes nonHodgkin's malignant lymphoma (large cell or immunoblastic), mucosal malignant melanoma, and rhabdomyosarcoma. Differentiation is readily achieved by appropriate immunohistochemical staining.
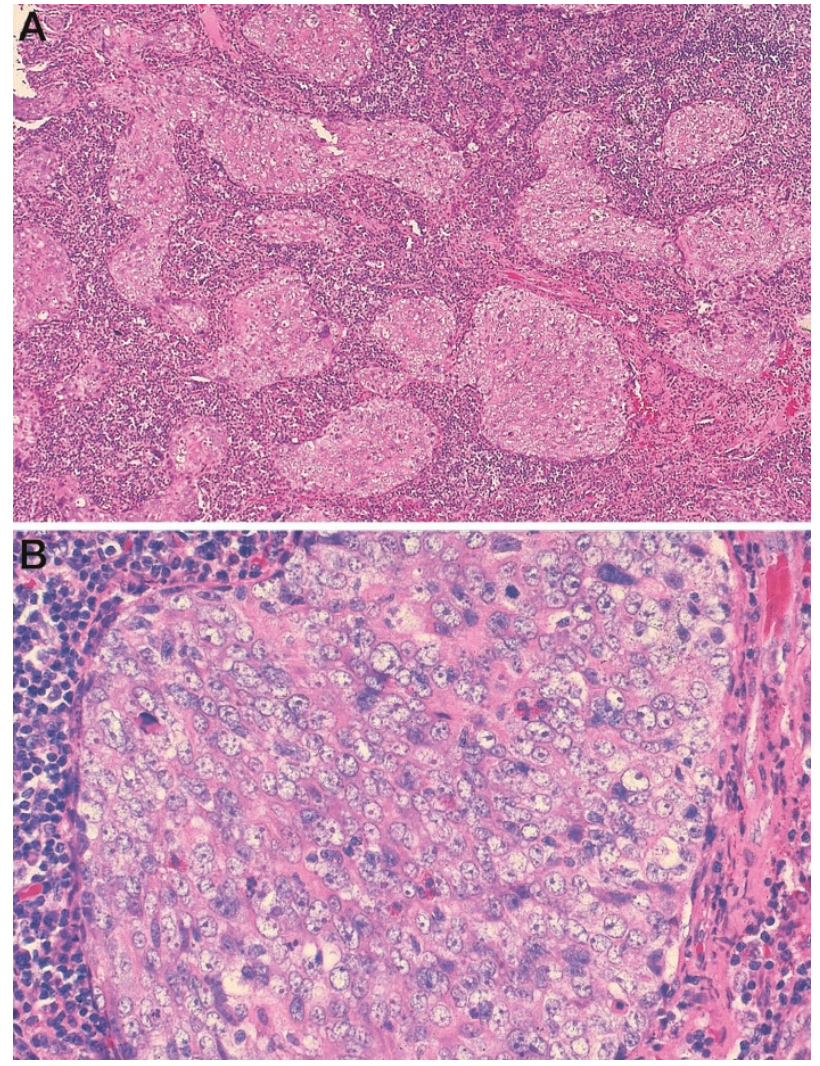

FIGURE 19. Nasopharyngeal nonkeratinizing carcinoma, undifferentiated type, cohesive growth. A, the neoplastic nests are readily identified, standing out as distinct nests or syncytium from the surrounding benign lymphocytic cell population. B, the neoplastic cells include enlarged nuclei with vesicular chromatin, indistinct cell borders, and prominent eosinophilic nucleoli.

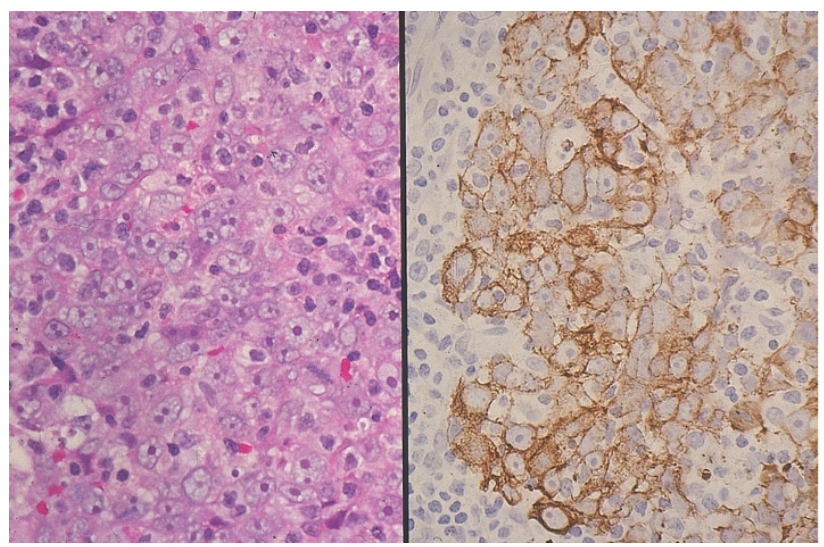

FIGURE 20. Nasopharyngeal nonkeratinizing carcinoma, undifferentiated type, diffuse growth. Left, in this pattern the differential diagnosis includes malignant lymphoma. Right, cytokeratin immunoreactivity confirms epithelial nature of the malignant infiltrate.

\section{Adenoid ("Acantholytic" or Angiosarcoma-Like) SCC}

Another histopathologic type of SCC, but not a unique clinicopathologic entity, is the adenoid SCC. This tumor generally arises in cutaneous sites of the head and neck and, less frequently, arises in mucosal sites of the upper aerodigestive tract, including 

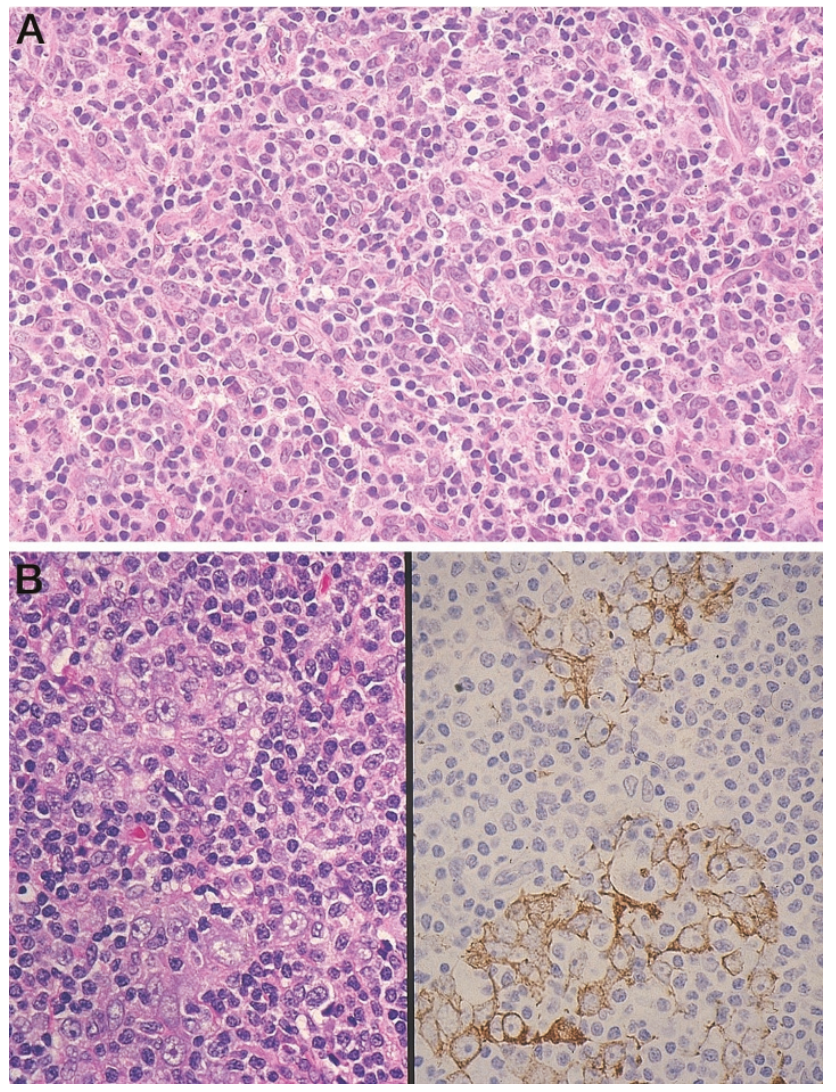

FIGURE 21. Nasopharyngeal nonkeratinizing carcinoma, undifferentiated type, diffuse growth. A, because of the absence of a desmoplastic response, the neoplastic cells may not be readily apparent. B, (left) at higher magnification, the neoplastic cells are more evident, but (right) cytokeratin immunoreactivity is needed to confirm the epithelial nature of the cells.

lip, oral cavity, tongue, and nasopharynx (76). Adenoid SCC resembles conventional SCC but because of acantholysis of the malignant squamous cells, pseudolumina are present that create the appearance of glandular differentiation (Fig. 22). True gland formation is not found in this tumor. Stains for mucin are negative. Immunoreactivity is present with epithelial markers (cytokeratin and EMA), but it is nonreactive with CD34, CD31, and Factor VIIIrelated antigen. Ultrastructural findings are typical of SCC (76).

The differential diagnosis may include adenocarcinoma, adenosquamous carcinoma, and angiosarcoma. The absence of epithelial mucin helps differentiate this tumor from adenocarcinoma and adenosquamous carcinoma. Grossly, adenoid SCC lack the overall appearance of angiosarcoma (a multinodular, violaceous lesion); immunohistochemistry and EM findings help differentiate angiosarcoma from adenoid SCC.

\section{Carcinogenesis, Field Cancerization, and Etiology of HNSCC}

In 1953, Slaughter et al. (77) introduced the concept of field cancerization, suggesting the impor-

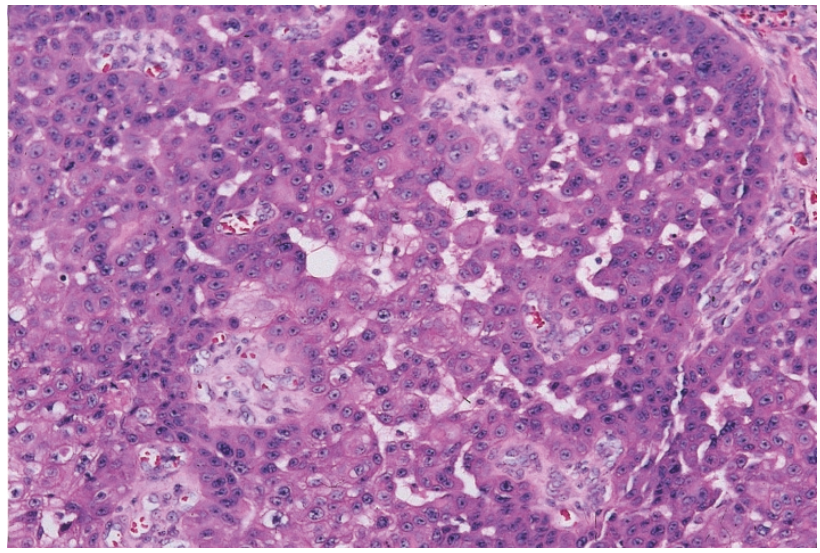

FIGURE 22. Adenoid squamous cell carcinoma. Because of acantholysis of the malignant squamous cells, pseudolumina are present, creating the appearance of glandular differentiation. True gland formation is not found.

tance of carcinogen activation of an entire exposed mucosa. These authors postulated that multiple, independent, carcinogenic events occurred in separate cells because of exposure of the "preconditioned epithelium" or "condemned mucosa" to a carcinogenic agent. The field of preconditioned epithelium or condemned mucosa became activated or developed into cancer, producing multiple, separate carcinomas, rather than the case being a single cell that becomes malignant (77). Subsequent studies confirmed the field cancerization phenomenon, in which significant dysplastic changes affect a wide epithelial mucosal field in patients at high risk for developing cancer (e.g., heavy smokers and drinkers; 78-80). The concepts of field cancerization and condemned mucosa explain the greater risk to the head and neck cancer patient for the development of a second primary malignancy that in turn plays a significant factor in the tendency for these tumors to recur or persist despite therapeutic intervention, with adverse impact on survival.

Using the same observation made by Slaughter et al. (77), Carey (81), and Worsham et al. (82) proposed an alternative hypothesis, suggesting that a single focus of tumor develops and spreads laterally by arborization without disrupting the adjacent normal mucosa. Worsham et al. (82) evaluated synchronous but separate carcinomas (primary floor of mouth and pyriform sinus lying 6 to $7 \mathrm{~cm}$ apart) and metachronous carcinomas (recurrences of these tumors after radiotherapy) in a single patient to determine whether the tumors were of common or independent clonal origin. Histologically, the two tumors shared a similar morphology, including invasive moderate to poorly differentiated keratinizing SCCs. The authors found that all four tumors were of monoclonal origin and suggested that in some patients, second primary cancers may arise at distant sites because of the lateral spread of malig- 


\begin{tabular}{|c|c|c|c|}
\hline Parameter & Keratinizing & Nonkeratinizing & Undifferentiated \\
\hline $\begin{array}{l}\text { Percentage of } \\
\text { Cases }\end{array}$ & Approximately 25\% & Least common $(<15 \%)$ & Most common $(>60 \%)$ \\
\hline Sex/Age & $\mathrm{M}>\mathrm{F} ; 6$ th decade & $\mathrm{M}>\mathrm{F} ; 6$ th decade & M > F; bimodal 2nd \& 6th decades \\
\hline Histology & $\begin{array}{l}\text { Keratinization, intercellular } \\
\text { bridges; conventional } \\
\text { squamous carcinoma graded } \\
\text { as well, moderately, or poorly } \\
\text { differentiated; desmoplastic } \\
\text { response to invasion }\end{array}$ & $\begin{array}{l}\text { Little to absent keratinization, } \\
\text { growth pattern similar to } \\
\text { transitional carcinoma of the } \\
\text { bladder; typically, absence of } \\
\text { dsemoplastic response to } \\
\text { invasion }\end{array}$ & $\begin{array}{l}\text { Absent keratinization; syncytial growth, } \\
\text { cohesive or noncohesive cells with } \\
\text { round nuclei, prominent eosinophilic } \\
\text { nucleoli, scant cytoplasm and mitoses; } \\
\text { prominent nonneoplastic lymphoid } \\
\text { component; typically, absence of } \\
\text { desmoplastic response to invasion }\end{array}$ \\
\hline IHC & CK positive & CK positive & CK positive; LCA and DES negative \\
\hline EBV & Weak association & Strong association & Strong association \\
\hline Treatment & Radioresponsiveness is not good & Variably radioresponsive & Radiosensitive \\
\hline Prognosis (5-year) & $10-20 \%$ survival & $35-50 \%$ survival & $60 \%$ survival \\
\hline
\end{tabular}

IHC = immunohistochemistry; CK = cytokeratin; LCA = leukocyte common antigen; DES = desmin.

nant clones. This lateral spread presupposes the multiple factors required for active neoplastic cell motility with penetration of extracellular matrices (83). Studies by Bedi et al. (84) and Califano et al. (85) support these observations. Bedi et al. (84), using X-chromosome inactivation and loss of heterozygosity (LOH) analysis in multiple HNSCC from eight female patients, showed high probability that second primary tumors were progeny of the same clone, supporting the idea that many second primary tumors represent extensions of the initial tumor clone. Califano et al. (85) demonstrated that apparently normal mucosa surrounding preinvasive and microinvasive HNSCCs shared common genetic aberrations with the tumor, supporting the concept proposed by Worsham and colleagues.

\section{Tobacco and Alcohol}

The most important risk factors in mucosal HNSCC are tobacco and alcohol (86). Both tobacco and alcohol represent independent risk factors for the development of HNSCC, and alcohol potentiates tobacco-related carcinogenesis (87, 88). Tobacco-related carcinogenesis is not limited to the smoking of tobacco products, but there is also a strong association between the use of smokeless tobacco and the development of oral squamous carcinoma. Numerous epidemiologic studies have shown the carcinogenic effects of tobacco and alcohol, as well as other exogenous factors, such as nutritional, occupational, and environmental ones, in the development of head and neck malignancies (89).

\section{Viruses}

There is increasing evidence that various viruses may be linked to the development of squamous carcinoma of the head and neck. A strong association exists between nasopharyngeal undifferentiated carcinoma and the presence of Epstein-Barr virus.
HPV infection has been seen in association with benign nonneoplastic lesions, benign neoplasms, premalignant lesions, and malignant neoplasms of the head and neck $(90,91)$. The HPV types that are considered low risk for malignant progression, including Types 6 and 11, are present in nonneoplastic lesions (keratoses) and benign papillomas of various mucosal sites of the upper aerodigestive tract. High-risk or oncogenic types of HPV have been found in squamous-type cancers of the head and neck (90). The mere presence of the virus in association with these tumors suggests a carcinogenic role, but a direct cause and effect remains elusive. HPV may play a role in the earliest stages of carcinogenesis and has been found in benign keratotic lesions and premalignant lesions (dysplasia) of the larynx $(10,90)$. Oncogenic types of HPV have been identified in cancerous lesions or lesions with a known potential to evolve into cancer, suggesting that HPV infection plays a significant factor in the development of SCC (90). An association between HPV infection and tobacco-linked keratosis or leukoplakia in oral cavity lesions has been shown, suggesting a synergistic role for tobacco and papillomavirus in the development of HNSCC (91). Viral induction appears to be a legitimate etiologic factor in the development of $\mathrm{VC}$, suggesting that it plays a direct active pathogenetic role of HPV, rather than is an innocent bystander, in the development of VC. The active role of HPV may be as a promoter in the multistep process of carcinogenesis in squamous cells of the UADT. Two viral oncoproteins of highrisk HPVs, E6 and E7, promote tumor progression by inactivation of p53 and retinoblastoma tumor suppressor gene products, respectively (92-94). These viral oncoproteins are capable of disrupting the cell-cycle regulatory pathways in the genetic progression to SCC. Dysfunction of the retinoblastoma gene product results in abnormal cell proliferation and the development of malignant tumors (93). 
More recently, Gillison et al. (94) reported evidence for a causal association between HPV and a subset of HNSCC. The results of this study apparently indicate that HPV-positive oropharyngeal cancers are likely causally associated with HPV infection. Mork and colleagues (95) found HPV-16 to be a risk factor for HNSCC but could not demonstrate a cause-and-effect relationship between HPV-16 infection and the development of HNSCC.

Interactions of susceptibility factors and exposure play a role in HNSCC (96) Susceptibility factors may be the reason that some individuals do not develop cancers despite long-term exposure, whereas others develop HNSCC at an early age with much less exposure. Susceptibility factors include immunologic factors and age. Susceptibility factors also exist for carcinogens. Genetic polymorphism in metabolizing enzymes (e.g., p450) may predispose a person for cancer development.

\section{Genetics of HNSCC}

The development of neoplasia is a process of clonal expansion and clonal evolution, which are thought to be driven by genetic and epigenetic changes affecting expression of genes that regulate normal homeostasis. Initial events may affect pathways that control cell cycle. Later events appear to alter functions associated with tissue organization, cellular migration, and failure to respond to death signals (96).

Evidence of a genetic predisposition to head and neck cancer has been known for some time. In 1932, Warren and Gates (97) suggested the possibility of a genetic predisposition or susceptibility in some individuals to the development of head and neck cancer. The sporadic occurrence of SCC in young adults and in nonusers of tobacco and alcohol suggests the possibility of genetic predisposition (98), although more recent studies suggest that in comparison to tumors of smokers, the tumors of nonsmokers contain a lower frequency of genetic alterations (99). Additional evidence for a genetic basis of carcinogenesis for HNSCC includes the presence of chromosomal alterations, including deletions, rearrangements, amplifications, and overexpressions in head and neck cancer (83) and mutagen-induced chromosomal fragility (100-107). Whether these genetic alterations occur independently, exclusive of other contributing carcinogenic factors, or whether they represent a multistep process occurring with or secondary to another carcinogenic stimulus remains to be determined.

\section{Mutagen Sensitivity}

Although exposure to a carcinogen is critical to the potential development of a head and neck ma- lignancy, host-specific factors also influence cancer risk by modulating the susceptibility to carcinogenic agents. The individual response to the mutagenic activity of exogenous agents resulting in defective DNA repair mechanisms, referred to as mutagen sensitivity, is a complex phenomenon involving multiple genetic factors (100-102). Mutagen sensitivity has been reported to be a significant risk factor for HNSCC, and the interaction between cigarette smoking and mutagen sensitivity has been shown to have a multiplicative effect $(103,104)$. The clinical follow-up of the mutagen-sensitive head and neck cancer patient has shown these patients to be at greater risk for developing a second primary malignancy, as compared with a control group of head and neck cancer patients who were less mutagen sensitive (105-107). Prospective studies of head and neck cancer patients have shown that mutagen sensitivity was a significant predictor of risk for developing a second primary malignancy and can be used as a "marker" for second primary malignancies (105-107).

\section{Molecular Biology and HNSCC}

\section{Past and Present}

Molecular biologic studies such as DNA hybridization and polymerase chain reaction (PCR) have been extensively used in patients with head and neck cancers in the evaluation of pathogenesis of disease and as potential determinants in prognosis. Point mutations, gene deletions and translocations, insertional mutagenesis, and amplification and overexpression of oncogenes/anti-oncogenes and tumor suppressor genes have been studied (38). Among the genetic markers that have been studied are the oncogenes $c$-erbB-2 (HER-2/neu), ras oncogene family (K-ras, H-ras, and $\mathrm{N}$-ras genes), the myc oncogene family ( $c$-myc and $N$-myc, L-myc), cyclin D1/CCND1 (PRAD-1), and the tumor suppressor genes p53 and retinoblastoma. Deletion, allelic imbalances, or LOH on short arm (p) of chromosome 3 occurs in HNSCC and have been shown to be associated aggressive biologic behavior (108), as well as having prognostic and therapeutic import (109). Molecular biologic studies have now been incorporated into the realm of intraoperative consultations. Brennan et al. (110) used molecular biologic markers to assess histopathologic negative surgical margins and negative lymph nodes for patients with SCC of the head and neck. The authors found p53 mutations in tumor resection margins and in lymph nodes that were free of tumor by conventional histologic examination. The presence of p53 mutations in "tumor-free" surgical margins and lymph nodes portended a substantially higher risk of local recurrent disease than in those patients without p53 mutations. 


\section{Present and Future-Comparative Genomic Hybridization and Microarrays}

Comparative genomic hybridization (CGH) is a technique used to visualize losses and gains of chromosomal segments using DNA extracted from tumor tissue (111). CGH is a powerful tool for screening tumors for genetic changes. CGH has been used in the evaluation of HNSCC showing frequent deletions in chromosome $3 p$ and frequent increases in chromosome $3 \mathrm{q}$, as well as in 11q13, $8 q, 19 q, 19 p$, and 17q (112-116). CGH has been used in attempts to predict prognosis in HNSCC (117), as a potential marker for clinical response (118), and to detect metastatic disease $(119,120)$.

\section{Functional Genomics}

Functional genomics allows for large-scale, genomicwide experimental approaches to study the roles that genes play in the cell $(96,121-125)$. Through functional genomics, thousands of genes can be studied simultaneously and quantitated, making it possible to compare a cell's gene activity at different time points or in different metabolic states. Functional genomics relies on the propensity of one strand of linked nucleotides to bind (hybridize) to its complementary strand. In comparison to other hybridization methods, functional genomics improves on the scale, specificity, sensitivity, speed, quantitation, and reproducibility achievable with hybridization. Microarrays have revolutionized the ability to detect genetic changes and to identify alterations in gene expression in tissues or cells.

The two current mainstays of functional genomics are the oligonucleotide chip referred to as the gene chip (genomic DNA arrays) and the gridded cDNA microarray chip (expression arrays). Oligonucleotide chips are thumbnail-sized silica glass squares enclosed in a plastic frame. On gene chips, photolithography is used to construct small synthetic oligonucleotide probes representing snippets or small segments of linked nucleotides (chromosomes) representing selected and highly characteristic regions of genes. The location of each chromosome is known, and then normal and tumor DNA labeled with different fluorochromes are mixed in equal amounts and hybridized to the array. A fluorescent reader determines the color of each spot. If the segment or gene is lost in the tumor, then the spot will hybridize predominantly with the normal DNA and will be stained red. If the gene is amplified in the tumor, then the spot will hybridize predominantly with the tumor DNA and will be stained green.

In contrast, the gridded cDNA microarray chips are standard glass microscopic slides on which are spotted PCR products of individual cDNA clones.
cDNA is a version of DNA that represents only those gene regions whose code is translated into protein. The cDNA probes deposited on microarray slides are composed of known genes whose functions are at least partially understood or of cDNA fragments called expressed sequence tags whose functions are not known and that contain no previously identified functional motifs. For the expression arrays, total RNA is collected from test and normal samples, and the expression of genes in the normal is compared with those in the test sample. To detect changes in gene expression associated with a tumor development, RNA is collected from fresh tissue (tumor and corresponding normal tissue). RNA is converted directly to cDNA using reverse transcription and the cDNA is used to probe the array (if the RNA is limited, then linear amplification is used). As with genomic arrays, the test cDNAs are tagged with fluorescent dyes, the test cDNA with green dye and the control is labeled with red dye. Genes that are up-regulated in the tumor will appear predominantly green, whereas those that have been shut off in the tumor will appear predominantly red.

Whether using oligonucleotide chip or cDNA microarray chip, the arrayed nucleic acid probes can be used to identify which of a cell's genes are expressed within it. Because the sample cDNA is derived from products of all of the cell's active genes, each hybridization event is evidence of gene expression. Because the identity and location of each oligonucleotide or cDNA probe within the array is known, the cellular genes that are expressed are also known. Visualizing and analyzing that expression is key. Gradations in hue indicate relative degrees of expression in two different cells, whereas variations in intensity of light emitted indicate differences in abundance.

To date, functional genomic analysis on HNSCC has been limited (126). Potential use of functional genomics with HNSCC may be in diagnosis, prognosis, and response to therapy.

\section{REFERENCES}

1. Mashberg A, Samit A. Early diagnosis of asymptomatic oral and oropharyngeal squamous cancers. CA Cancer J Clin 1995;45:328-51.

2. Silverman S, Gorsky M, Lozada F. Oral leukoplakia and malignant transformation. Cancer 1984;53:563-8.

3. Mashberg A. Erythroplasia: the earliest sign of asymptomatic oral cancer. J Am Dent Assoc 1978;96:615-20.

4. Mashberg A, Feldman LJ. Clinical criteria for identifying early oral and oropharyngeal carcinoma: erythroplasia revisited. Am J Surg 1988;156:273-5.

5. Crissman JD, Zarbo RJ. Quantitation of DNA ploidy in squamous intraepithelial neoplasia of the laryngeal glottis. Arch Otolaryngol Head Neck Surg 1991;117:182-8.

6. Fechner RE, Mills SE. Premalignant lesions of the larynx. In: Silver C, editor. The larynx. Philadelphia: Saunders; 1991. p. $2-5$. 
7. Crissman JD, Gnepp DR, Goodman ML, Hellquist H, Johns ME. Pre-invasive lesions of the upper aerodigestive tract. Histologic definitions and clinical implications (a symposium). Pathol Annu 1987(1);22:311-53.

8. Blackwell KE, Fu YS, Calcaterra TC. Laryngeal dysplasia. A clinicopathologic study. Cancer 1995;75:457-63.

9. Mills SE, Gaffey MJ, Frierson HF Jr. Conventional squamous cell carcinoma. In: Rosai J, Sobin LW (Eds.), Tumors of the upper aerodigestive tract and ear. Atlas of tumor pathology. Fascicle 26. 3rd series. Washington, DC: Armed Forces Institute of Pathology. 2000:45-70.

10. Crissman JD, Zarbo RJ. Dysplasia, in situ carcinoma, and progression to invasive squamous cell carcinoma of the upper aerodigestive tract. Am J Surg Pathol 1989;13(1 Suppl):5-16.

11. Friedmann I, Ferlito A. Precursors of squamous cell carcinoma. In: Ferlito A, editors. Neoplasms of the larynx. Edinburgh, Scotland: Churchill Livingstone; 1993. p. 97-111.

12. Gale N, Kambič V, Michaels L, et al. The Ljubljana classification: a practical strategy for the diagnosis of laryngeal precancerous lesions. Adv Anat Pathol 2000;4:240-51.

13. Crissman JD. Laryngeal keratosis and subsequent carcinoma. Head Neck Surg 1979;1:386-91.

14. McGavran MH, Bauer WC, Ogura JH. Isolated laryngeal keratosis: its relation to carcinoma of the larynx based on clinicopathologic study of 87 consecutive cases with longterm follow-up. Laryngoscope 1960;70:932-51.

15. Norris CM, Peale AR. Keratosis of the larynx. J Laryngol Otol 1963;77:635-47.

16. Gabriel CE, Jones DG. Hyperkeratosis of the larynx. J Laryngol Otol 1973;87:129-34.

17. Henry RC. The transformation of laryngeal leukoplakia to cancer. J Laryngol Otol 1979;93:447-59.

18. Barnes L. Diseases of the larynx, hypopharynx and esophagus. In: Barnes L, editor. Surgical pathology of the head and neck. New York: Dekker; 2001. p. 127-237.

19. Bouquot JE, Gnepp DR. Laryngeal precancer: a review of the literature, commentary, and comparison with oral leukoplakia. Head Neck 1991;13:488-97.

20. Hellquist H, Lundgren J, Oloffsson J. Hyperplasia, keratosis, dysplasia and carcinoma in situ of the vocal cords-a follow-up study. Clin Otolaryngol 1982;7:11-27.

21. Crissman JD, Zarbo RJ. Quantitation of DNA ploidy in squamous intraepithelial neoplasia of the laryngeal glottis. Arch Otolaryngol Head Neck Surg 1991;117:182-8.

22. Miller AH, Fisher HR. Clues to the life history of carcinoma in-situ of the larynx. Laryngoscope 1971;81:1475-80.

23. Crissman JD, Zarbo RJ, Drozdowicz S, et al. Carcinoma in-situ and microinvasive squamous carcinoma of the laryngeal glottis. Arch Otolaryngol Head Neck Surg 1988;114 299-307.

24. Bauer WC, McGavran MH. Carcinoma in situ and evaluation of epithelial changes in laryngopharyngeal biopsies. J Am Med Assoc 1972;221:72-5.

25. Böcking A, Auffermann W, Vogel $\mathrm{H}$, et al. Diagnosis and grading of malignancy in 23 squamous epithelial lesions of the larynx with DNA cytomorphometry. Cancer 1985;56: $1600-4$.

26. Auerbach O, Hammond EC, Garfinkel L. Histologic changes in the larynx in relation to smoking habits. Cancer 1970;25: 92-8.

27. Sakr WA, Zarbo RJ, Jacobs JR, Crissman JD. Distribution of basement membrane in squamous cell carcinoma of the head and neck. Hum Pathol 1987;18:1043-50.

28. Miller AH. Carcinoma in situ of the larynx - clinical appearance and treatment. In: Alberti PW, Bryce DP, editors. Centennial conference on laryngeal carcinoma. New York Appleton-Century-Crofts; 1976.
29. Gillis TM, Incze MS, Vaughan CW, Simpson GT. Natural history and management of keratosis, atypia, carcinoma in situ and microinvasive cancer of the larynx. Am J Surg 1983;146:512-6.

30. Padovan IF. Premalignant laryngeal lesions-a laryngologist's viewpoint. In: Alberti PW, Bryce DP, editors. Centennial conference on laryngeal carcinoma. New York: Appleton-Century-Crofts; 1976.

31. Friedmann I. Precancerous lesions of the larynx. In: Alberti PW, Bryce DP, editors. Centennial conference on laryngeal carcinoma. New York: Appleton-Century-Crofts; 1976.

32. DeSanto LW. Cancer of the supraglottic larynx: a review of 260 patients. Otolaryngol Head Neck Surg 1985;93:705-11.

33. Carbone A, Micheau C, Bosq J, Caillaud J-M, Vandenbrouck C. Superficial extending carcinoma of the hypopharynx: report of 26 cases of an underestimated carcinoma. Laryngoscope 1983;93:1600-6.

34. Ferlito A, Carbone A, DeSanto LW, et al. "Early" cancer of the larynx: the concept as defined by clinicians, pathologists, and biologists. Ann Otol Rhinol Laryngol 1996;105: 245-50.

35. Mills SE, Gaffey MJ, Frierson HF Jr. Benign squamous proliferations. In: Rosai J, Sobin LW (Eds.), Tumors of the upper aerodigestive tract and ear. Atlas of tumor pathology. Fascicle 26. 3rd series. Washington, DC: Armed Forces Institute of Pathology; 2000. p. 21-44.

36. Mills SE, Gaffey MJ, Frierson HF Jr. Miscellaneous tumorlike lesions. In: Tumors of the upper aerodigestive tract and ear. Atlas of tumor pathology. Fascicle 26. Third series. Washington, DC: Armed Forces Institute of Pathology; 2000. p. 355-82.

37. Crissman JD, Liu WY, Gluckman JL, Cummings G. Prognostic value of histopathologic parameters in squamous cell carcinoma of the oropharynx. Cancer 1984;54:2995-3001.

38. Wenig BM. General principles of head and neck pathology. In: Harrison LB, Sessions RB, Hong WK, editors. Head and neck cancer. Philadelphia: Lippincott-Raven; 1999. p. 253349.

39. Lampe HB. DNA analysis of head and neck squamous cell carcinoma by flow cytometry. Laryngoscope 1993;103:63744.

40. Sakr W, Hussan M, Zarbo RL, Ensley J, Crissman JD. DNA quantification and histologic characteristics of squamous cell carcinoma of the upper aerodigestive tract. Arch Pathol Lab Med 1989;113:1009-14.

41. Watling DL, Gown AM, Coltrera MD. Overexpression of p53 in head and neck cancer. Head Neck 1992;14:437-44.

42. El-Naggar AK, Steck K, Batsakis JG. Heterogeneity of the proliferative fraction and cyclin D1/CCND1 gene amplification in head and neck squamous cell carcinoma. Cytometry 1995;21:47-51.

43. Crissman JD, Kessis T, Shah KV, et al. Squamous papillary neoplasia of the upper aerodigestive tract. Hum Pathol 1988;19:1387-96.

44. Thompson LDR, Wenig BM, Heffner DK, Gnepp DR. Exophytic and papillary squmaous cell carcinoma of the larynx: a clinicopathologic series of 104 cases. Otolaryngol Head Neck Surg 1999;120:718-24.

45. Suarez PA, Adler-Storthz K, Luna MA, et al. Papillary squamous cell carcinomas of the upper aerodigestive tract: a clinicopathologic and molecular study. Head Neck 2000;22: $360-8$

46. Batsakis JG, Hybels R, Crissman JD, Rice DH. The pathology of head and neck tumors: verrucous carcinoma, part 15 . Head Neck Surg 1982;5:29-38.

47. Ferlito A, Recher G. Ackerman's tumor (verrucous carcinoma) of the larynx. A clinicopathologic study of 77 cases. Cancer 1980;46:1617-30. 
48. Medina JE, Dichtel W, Luna MA. Verrucous-squamous carcinomas of the oral cavity. A clinicopathologic study of 104 cases. Arch Otolaryngol 1984;110:437-40.

49. Luna MA, Tortoledo ME. Verrucous carcinoma. In: Gnepp DR, ed. Pathology of the head and neck. New York: Churchill Livingstone; 1988. p. 497-515.

50. Shear M, Pindborg JJ. Verrucous hyperplasia of the oral mucosa. Cancer 1980;46:1855-62.

51. Hansen LS, Olson JA, Silverman S. Proliferative verrucous leukoplakia. A long-term study of thirty patients. Oral Surg Oral Med Oral Pathol 1985;60:285-98.

52. Murrah VA, Batsakis JG. Proliferative verrucous leukoplakia and verrucous hyperplasia. Ann Otol Rhinol Laryngol 1994; 103:660-3.

53. Batsakis JG, Suarez P, el-Naggar AK. Proliferative verrucous leukoplakia and its related lesions. Oral Oncol 1999;35: 354-9.

54. Fechner RE, Mills SE. Verruca vulgaris of the larynx. A distinctive lesion of probable viral origin confused with verrucous carcinoma. Am J Surg Pathol 1982;6:357-62.

55. Berthelet E, Shenouda G, Black MJ, et al. Sarcomatoid carcinoma of the head and neck. Am J Surg 1994;168:455-8.

56. Zarbo RJ, Crissman JD, Venkat H, Weiss MA. Spindle-cell carcinoma of the aerodigestive tract mucosa: an immunohistologic and ultrastructural study of 18 biphasic tumors and comparison with seven monophasic spindle-cell tumors. Am J Surg Pathol 1986;10:741-53.

57. Ellis GL, Langloss JM, Heffner DK, Hyams VJ. Spindle-cell carcinoma of the aerodigestive tract: an immunohistochemical analysis of 21 cases. Am J Surg Pathol 1987;11: 335-42.

58. Lewis JE, Olsen KD, Sebo TJ. Spindle cell carcinoma of the larynx: review of 26 cases including DNA content and immunohistochemistry. Hum Pathol 1997:28:664-73.

59. Nakleh RE, Zarbo RJ, Ewing S, Carey JL, Gown AM. Myogenic differentiation in spindle cell (sarcomatoid) carcinoma of the upper aerodigestive tract. Appl Immunohistochem 1993;1:58-68.

60. Ophir D, Marshak G, Czernobilsky B. Distinctive immunohistochemical labeling of epithelial and mesenchymal elements in laryngeal pseudosarcoma. Laryngoscope 1987;97: $490-4$.

61. Ellis G, Langloss JM, Enzinger FM. Coexpression of keratin and desmin in a carcinosarcoma involving the maxillary alveolar ridge. Oral Surg Oral Med Oral Pathol 1985;60: 410-6.

62. Balercia G, Bhan AK, Dickersin GR. Sarcomatoid carcinoma: an ultrastructural study with light microscopic and immunohistochemical correlation of 10 cases from various anatomic sites. Ultrastruct Pathol 1995;19:249-63.

63. Ansari-Lari MA, Westra WH. Immunohistochemical p53 expression patterns in sarcomatoid carcinomas of the upper respiratory tract [Abstract]. Mod Pathol 2001;14:148A.

64. Wenig BM, Devaney K. Bisceglia M. Inflammatory myofibroblastic pseudotumors of the larynx: a clinicopathologic report of eight cases including immunohistochemical and ultrastructural analysis. Cancer 1995;76:2217-29.

65. Cook JR, Dehner LP, Collins MH, Ma Z, Morris SW, Coffin CM, Hill DA. Anaplastic lymphoma kinase (ALK) expression in the inflammatory myofibroblastic tumor. A comparative immunohistochemical study. Am J Surg Pathol 2001;28: 1364-71.

66. Rubin BP, Lawrence BD, Perez-Atayde A, Xiao S, Yi ES, Fletcher CDM, et al. TPM-ALK fusion genes and ALK expression in inflammatory myofibroblastic tumor. Mod Pathol 2000;13:15A.

67. Wain SL, Kier R, Vollmer RT, Bossen EH. Basaloidsquamous carcinoma of the tongue, hypopharynx and larynx. Hum Pathol 1986;17:1158-66.
68. Banks ER, Frierson HF Jr, Mills SE, et al. Basaloid squamous cell carcinoma of the head and neck: a clinicopathologic and immunohistochemical study of 40 cases. Am J Surg Pathol 1992;16:939-46.

69. Weineke J, Thompson LDR, Wenig BM. Basaloid squamous cell carcinoma of the nasal cavity and paranasal sinuses. Cancer 1999;85:841-54.

70. Morice WG, Ferreiro JA. Distinction of basaloid squamous cell carcinoma from adenoid cystic and small cell undifferentiated carcinoma by immunohistochemistry. Hum Pathol 1998;29:609-12.

71. Hewan-Lowe K, Dardick I. Ultrastructural distinction of basaloid-squamous carcinoma and adenoid cystic carcinoma. Ultrastruct Pathol 1995;19:371-81.

72. Shanmugaratnam K, Sobin LH, Barnes L, et al. World health organization histological classification of tumours. Histological typing of tumours of the upper respiratory tract and ear. 2nd ed. Berlin: Springer-Verlag; 1991.

73. Ferlito A, Weiss LM, Rinaldo A, et al. Lymphoepithelial carcinoma of the larynx, hypopharynx, and trachea. Ann Otol Rhinol Laryngol 1997;106:437-44.

74. MacMillan C, Kapadia SB, Finkelstein SD, et al. Lymphoepithelial carcinoma of the larynx and hypopharynx: study of eight cases with relationship to Epstein-Barr virus (EBV) and p53gene alterations, and review of the literature. Hum Pathol 1996;27:1172-9.

75. Pacchioni D, Negro F, Valente G, Bussolati G. Epstein-Barr virus by in situ hybridization in fine-needle aspiration biopsies. Diagn Mol Pathol 1994;3:100-4.

76. Mills SE, Gaffey MJ, Frierson HF Jr. Squamous cell carcinoma variants. In: Rosai J, Sobin LW (Eds.), Tumors of the upper aerodigestive tract and ear. Atlas of tumor pathology. Fascicle 26. Third series. Washington, DC: Armed Forces Institute of Pathology; 2000. p. 71-106.

77. Slaughter DP, Southwick HW, Smejkal W. "Field cancerization" in oral stratified squamous epithelium. Clinical implications of multicentric origin. Cancer 1953;6:963-8.

78. Berg JW, Schottenfeld D, Ritter F. Incidence of multiple primary cancers. III. Cancers of the respiratory and upper digestive system as multiple primary cancers. J Natl Cancer Inst 1970;44:263-71.

79. Cohn AM, Peppard SB. Multiple primary malignant tumors of the head and neck. Am J Otolaryngol 1980;1:411-7.

80. Licciardello JTW, Spitz MR, Hong WK. Multiple primary cancer in patients with cancer of the head and neck: second cancer of the head and neck, esophagus and lung. Int J Radiat Oncol Biol Phys 1989;17:467-76.

81. Carey TE. Field cancerization: are multiple primary cancers monoclonal or polyclonal? Ann Med 1996;28:183-8.

82. Worsham MJ, Wolman SR, Carey TE, Zarbo RJ, Benninger MS, Van Dyke DL. Common clonal origin of synchronous primary head and neck squamous cell carcinomas: analysis by tumor karyotypes and fluoresence in situ hybridization. Hum Pathol 1995;26:251-61.

83. Stetler-Stevenson WG, Aznavoorian S, Liotta LA. Tumor cell interactions with the extracellular matrix during invasion and metastasis. Ann Rev Cell Biol 1993;9:541-73.

84. Bedi GC, Westra WH, Gabrielson E, et al. Multiple head and neck tumors: evidence for common clonal origin. Can Res 1995;26:251-61.

85. Califano J, van der Riet P, Westra W, et al. Genetic progression model for head and neck cancer: implications for field cancerization. Cancer Res 1996;56:2484-7.

86. Decker J, Goldstein JC. Risk factors in head and neck cancer. N Engl J Med 1982;306:1151-5.

87. Vokes EE, Weichselbaum RR, Lippman SM, Hong WK. Head and neck cancer. N Engl J Med 1993;328:184-94. 
88. Franceschi S, Talamini R, Barra S, et al. Smoking and drinking in relation to cancers of the oral cavity, pharynx, larynx and esophagus in northern Italy. Cancer Res 1990;50:6502-7.

89. Schantz SP, Yu G. Epidemiology. In: Fu YS, Wenig BM, Abeymayor E, Wenig BL, editors. Head and neck pathology with clinical correlations. Philadelphia: Churchill Livingstone. 2000:38-61.

90. Fouret P, Martin F, Flahault A, Saint-Guily JL. Human papillomavirus infection in the malignant and premalignant head and neck epithelium. Diagn Mol Pathol 1995;4:122-7.

91. Greer RO, Eversole LR, Crosby LK. Detection of human papillomavirus-genomic DNA in oral epithelial dysplasia, oral smokeless tobacco-associated leukoplakias, and epithelial malignancies. J Oral Maxillofac Surg 1990;48:1201-5.

92. McKaig RG, Baric RS, Olshan AF. Human papillomavirus and head and neck cancer: epidemiology and molecular biology. Head Neck 1998;20:250-65.

93. Dyson N, Howley PM, Münger K, Harlow E. The human papillomavirus-16 E7 oncoprotein is able to bind the retinoblastoma gene product. Science 1989;243:934-7.

94. Gillison ML, Koch WM, Capone RB, et al. Evidence for a causal association between human papillomavirus and a subset of head and neck cancers. J Natl Cancer Inst 2000; 92:709-20.

95. Mork J, Lie K, Glattre E, et al. Human papillomavirus infection as a risk factor for squamous-cell carcinoma of the head and neck. N Engl J Med 2001;344:1125-31.

96. Carey TE, Wennenberg J. Cellular and molecular biology of the cancer cell. In: Fu YS, Wenig BM, Abeymayor E, Wenig BL, editors. Head and neck pathology with clinical correlations. Philadelphia: Churchill Livingstone; 2000. p. 3-37.

97. Warren S, Gates DC. Multiple primary malignant tumors: a survey of the literature and statistical study. Am J Cancer 1932;16:1358-414.

98. Lund VJ, Howard DJ. Head and neck cancer in the young: a prognostic conundrum? J Laryngol Otol 1990;104:544-8.

99. Koch WM, Lango M, Sewell D, et al. Head and neck cancer in nonsmokers: a distinct clinical and molecular entity. Laryngoscope 1999;109:1544-61.

100. Hsu TC. Genetic predisposition to cancer with special reference to mutagen sensitivity. In Vitro Cell Dev Biol 1987; 23:591-603.

101. Cherry LM, Hsu TC. Bleomycin-induced chromosome damage in lymphocytes of medullary lymphoid carcinoma patients and their family members. Anticancer Res 1983;3: 367-72.

102. Hsu TC, Johnston DA, Cherry LM. Sensitivity to genotoxic effects of bleomycin in humans: possible relationship to environmental carcinogenesis. Int J Cancer 1989;43:403-9.

103. Spitz MR, Fueger JJ, Beddingfield NA, et al. Chromosome sensitivity to bleomycin-induced mutagenesis as independent risk factor for aerodigestive tract cancers. Cancer Res 1989;49:4626-8.

104. Spitz MR, Fueger JJ, Halabi S, et al. Mutagen senstivity in upper aerodigestive tract cancer: a case-control analysis. Cancer Epidemiol Biomarkers Prev 1993;2:329-33.

105. Schantz SP, Spitz MR, Hsu TC. Mutagen sensitivity in patients with head and neck cancer: a biologic marker for risk of multiple primary malignancies. J Natl Cancer Inst 1990; 82:1773-5.

106. Spitz MR, Hoque A, Trizina Z, et al. Mutagen sensitivity as a risk factor for second malignant tumors following malignancies of the upper aerodigestive tract. J Natl Cancer Inst 1994;86:1681-4.

107. Hsu TC, Spitz MR, Schantz SP. Mutagen sensitivity: a biologic marker of cancer susceptibility. Cancer Epidemiol Biomarkers Prev 1991;1:83-9.
108. El-Naggar A, Lee MS, Wang G, et al. Polymerase chain reaction-based restriction fragment length polymorphism analysis of the short arm of chromosome 3 in primary head and neck squamous carcinoma. Cancer 1993;72:881-6.

109. Li X, Lee NK, Ye YW, et al. Allelic loss at chromosome 3p, $8 p, 13 q$, and $17 p$ associated with poor prognosis in head and neck cancer. J Natl Cancer Inst 1994;86:1524-9.

110. Brennan JA, Mao L, Hruban RH, et al. Molecular assessment of histopathological staging in squamous-cell carcinoma of the headand neck. N Engl J Med 1995;332:429-35.

111. Kallioniemi A, Kallioniemi OP, Sudar D, et al. Comparative genomic hybridization for molecular cytogenetic analysis of solid tumors. Science 1992;258:818-21.

112. Bockmuhl U, Schwendel A, Dietel M, Petersen I. Distinct patterns of chromosomal alterations in high- and lowgrade head and neck squamous cell carcinomas. Cancer Res 1996;56:5325-9.

113. Speicher MR, Howe C, Crotty P, et al. Comparative genomic hybridization detects novel deletions and amplifications in head and neck squamous cell carcinomas. Cancer Res 1995; 55:1010-3.

114. Brzoska PM, Levin NA, Fu KK, et al. Frequent novel DNA copy number increase in squamous cell head and neck tumors. Cancer Res 1995;55:3055-9.

115. Stafford ND, Ashman JN, MacDonald AW, et al. Genetic analysis of head and neck squamous cell carcinoma and surrounding mucosa. Arch Otolaryngol Head Neck Surg 1999;125:1341-8.

116. Bockmuhl U, Wolf G, Schmidt S, et al. Genomic alterations associated with malignancy in head and neck cancer. Head Neck 1998;20:145-51.

117. Bockmuhl U, Kuchler I, Petersen I. Improved prognostic assessment of head-neck carcinomas by new genetic markers. Hals-Nason-Olrenheikunde 2000;48:451-6.

118. Bergamo NA, Rogatto SR, Poli-Frederico RC, et al. Comparative genomic hybridization analysis detects frequent overrepresentation of DNA sequences at $3 q, 7 p$, and $8 q$ in head and neck carcinomas. Cancer Genet Cytogenet 2000;119: $48-55$.

119. Bockmuhl U, Petersen S, Schmidt S, et al. Patterns of chromosomal alterations in metastasizing and nonmetastasizing primary head and neck carcinomas. Cancer Res 1997; 57:5213-6.

120. Welkoborsky HJ, Bernauer HS, Riazimand HS, et al. Patterns of chromosomal aberrations in metastasizing and nonmetastasizing squamous cell carcinomas of the oropharynx and hypopharynx. Ann Otol Rhinol Laryngol 2000; 4:401-10.

121. Golub TR, Slonim DK, Tamayo P, et al. Molecular classification of cancer: class discovery and gene expression monitoring. Science 1999;286:531-7.

122. Nat Genet 1999;21(Suppl):1-60.

123. Ferea TL, Brown PO. Observing the living genome. Curr Opin Genet Devel 1999;9:715-22.

124. Perou CM, Jeffrey SS, van de Run M, et al. Distinctive gene expression patterns in human mammary epithelial cells and breast cancers. Proc Natl Acad Sci USA 1999;96: 9212-7.

125. Ross DT, Scherf U, Eisen MB, et al. Systematic variation in gene expression patterns in human cancer cell lines. Nat Genet 2000;24:227-335.

126. Belbin TJ, Singh B, Barber I, et al. Molecular classification of head and neck squamous cell carcinoma using CDNA microassays. Cancer Res 2002;62:1184-90. 